Cochrane Database of Systematic Reviews

\title{
Antibiotic prophylaxis for operative vaginal delivery (Review)
}

\author{
Liabsuetrakul T, Choobun T, Peeyananjarassri K, Islam QM
}

Liabsuetrakul T, Choobun T, Peeyananjarassri K, Islam QM.

Antibiotic prophylaxis for operative vaginal delivery.

Cochrane Database of Systematic Reviews 2020, Issue 3. Art. No.: CD004455.

DOI: 10.1002/14651858.CD004455.pub5.

www.cochranelibrary.com 
TABLE OF CONTENTS

HEADER 1

ABSTRACT

PLAIN LANGUAGE SUMMARY

SUMMARY OF FINDINGS

2

BACKGROUND

OBJECTIVES

METHODS

RESULTS

Figure 1.

Figure 2.

Figure 3.

DISCUSSION

AUTHORS' CONCLUSIONS

ACKNOWLEDGEMENTS

REFERENCES

CHARACTERISTICS OF STUDIES

DATA AND ANALYSES

Analysis 1.1. Comparison 1 Any antibiotics versus placebo or no treatment, Outcome 1 Infected episiotomy/laceration (superficial perineal wound infection).

Analysis 1.2. Comparison 1 Any antibiotics versus placebo or no treatment, Outcome 2 Infected episiotomy/laceration (deep perineal wound infection).

Analysis 1.3. Comparison 1 Any antibiotics versus placebo or no treatment, Outcome 3 Infected episiotomy/laceration (organ or space infection).

Analysis 1.4. Comparison 1 Any antibiotics versus placebo or no treatment, Outcome 4 Infected episiotomy/laceration (wound breakdown).

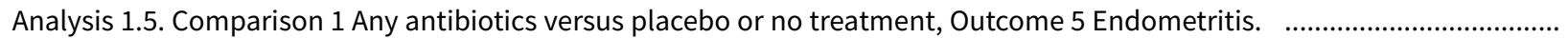
Analysis 1.6. Comparison 1 Any antibiotics versus placebo or no treatment, Outcome 6 Serious infectious complications. ...... Analysis 1.7. Comparison 1 Any antibiotics versus placebo or no treatment, Outcome 7 Confirmed or suspected maternal infection.

Analysis 1.8. Comparison 1 Any antibiotics versus placebo or no treatment, Outcome 8 Maternal adverse reactions. .............. Analysis 1.9. Comparison 1 Any antibiotics versus placebo or no treatment, Outcome 9 Maternal length of stay. ..................... Analysis 1.10. Comparison 1 Any antibiotics versus placebo or no treatment, Outcome 10 Perineal pain. .............................. Analysis 1.11. Comparison 1 Any antibiotics versus placebo or no treatment, Outcome 11 Use of pain relief for perineal pain. .. Analysis 1.12. Comparison 1 Any antibiotics versus placebo or no treatment, Outcome 12 Need for additional perineal care. ... Analysis 1.13. Comparison 1 Any antibiotics versus placebo or no treatment, Outcome 13 Dyspareunia.

Analysis 1.14. Comparison 1 Any antibiotics versus placebo or no treatment, Outcome 14 Breastfeeding at 6 weeks.

Analysis 1.15. Comparison 1 Any antibiotics versus placebo or no treatment, Outcome 15 Perineum "ever too painful or uncomfortable" to feed baby.

Analysis 1.16. Comparison 1 Any antibiotics versus placebo or no treatment, Outcome 16 Any primary care or home visits in relation to perineum.

Analysis 1.17. Comparison 1 Any antibiotics versus placebo or no treatment, Outcome 17 Any outpatient visits in relation to perineum.

Analysis 1.18. Comparison 1 Any antibiotics versus placebo or no treatment, Outcome 18 Maternal hospital re-admission. .... Analysis 1.19. Comparison 1 Any antibiotics versus placebo or no treatment, Outcome 19 Maternal health-related quality of life.

Analysis 1.20. Comparison 1 Any antibiotics versus placebo or no treatment, Outcome 20 Costs (£).

APPENDICES

WHAT'S NEW

HISTORY

CONTRIBUTIONS OF AUTHORS

DECLARATIONS OF INTEREST

SOURCES OF SUPPORT 
[Intervention Review]

\title{
Antibiotic prophylaxis for operative vaginal delivery
}

\author{
Tippawan Liabsuetrakul ${ }^{1}$, Thanapan Choobun ${ }^{2}$, Krantarat Peeyananjarassri2 ${ }^{2}$, Q Monir Islam³
}

1Epidemiology Unit, Faculty of Medicine, Prince of Songkla University, Hat Yai, Thailand. 2Department of Obstetrics and Gynecology, Faculty of Medicine, Prince of Songkla University, Hat Yai, Thailand. ${ }^{3}$ Liverpool School of Tropical Medicine, Liverpool, UK

Contact address: Tippawan Liabsuetrakul, Epidemiology Unit, Faculty of Medicine, Prince of Songkla University, Hat Yai, Songkhla, 90110, Thailand. tippawan.l@psu.ac.th, Itippawa@hotmail.com.

Editorial group: Cochrane Pregnancy and Childbirth Group.

Publication status and date: New search for studies and content updated (conclusions changed), published in Issue 3, 2020.

Citation: Liabsuetrakul T, Choobun T, Peeyananjarassri K, Islam QM. Antibiotic prophylaxis for operative vaginal delivery. Cochrane Database of Systematic Reviews 2020, Issue 3. Art. No.: CD004455. DOI: 10.1002/14651858.CD004455.pub5.

Copyright @ 2020 The Cochrane Collaboration. Published by John Wiley \& Sons, Ltd.

\section{A B S T R A C T}

\section{Background}

Vacuum and forceps assisted vaginal deliveries are reported to increase the incidence of postpartum infections and maternal readmission to hospital compared to spontaneous vaginal delivery. Prophylactic antibiotics may be prescribed to prevent these infections. However, the benefit of antibiotic prophylaxis for operative vaginal deliveries is still unclear. This is an update of a review last published in 2017.

\section{Objectives}

To assess the effectiveness and safety of antibiotic prophylaxis in reducing infectious puerperal morbidities in women undergoing operative vaginal deliveries including vacuum or forceps delivery, or both.

\section{Search methods}

For this update, we searched Cochrane Pregnancy and Childbirth's Trials Register, ClinicalTrials.gov, the WHO International Clinical Trials Registry Platform (ICTRP) (5 July 2019), and reference lists of retrieved studies.

\section{Selection criteria}

All randomised controlled trials comparing any prophylactic antibiotic regimens with placebo or no treatment in women undergoing vacuum or forceps deliveries were eligible. Participants were all pregnant women without evidence of infections or other indications for antibiotics of any gestational age. Interventions were any antibiotic prophylaxis (any dosage regimen, any route of administration or at any time during delivery or the puerperium).

\section{Data collection and analysis}

Two review authors assessed trial eligibility and risk of bias. Two review authors extracted the data independently using prepared data extraction forms. Any discrepancies were resolved by discussion and a consensus reached through discussion with all review authors. We assessed methodological quality of the two included studies using the GRADE approach.

\section{Main results}

Two studies, involving 3813 women undergoing either vacuum or forceps deliveries, were included. One study involving 393 women compared the antibiotic intravenous cefotetan after cord clamping compared with no treatment. The other study involving 3420 women compared a single dose of intravenous amoxicillin and clavulanic acid with placebo using $20 \mathrm{~mL}$ of intravenous sterile $0.9 \%$ saline.

The evidence suggests that prophylactic antibiotics reduce superficial perineal wound infection (risk ratio (RR) 0.53 , 95\% confidence interval $(\mathrm{Cl}) 0.40$ to 0.69 ; women $=3420$; 1 study; high-certainty evidence), deep perineal wound infection (RR $0.46,95 \% \mathrm{Cl} 0.31$ to 0.69 ; women = 3420; 1 study; high-certainty evidence) and probably reduce wound breakdown (RR 0.52, $95 \% \mathrm{Cl} 0.43$ to 0.63 ; women = 2593; 
1 study; moderate-certainty evidence). We are unclear about the effect on organ or space perineal wound infection (RR $0.11,95 \% \mathrm{Cl}$ 0.01 to 2.05 ; women $=3420 ; 1$ study) and endometritis (average RR $0.32,95 \% \mathrm{Cl} 0.04$ to $2.64 ; 15 / 1907$ versus $30 / 1906 ;$ women $=3813 ; 2$ studies) based on low-certainty evidence with wide Cls that include no effect. Prophylactic antibiotics probably lower serious infectious complications (RR $0.44,95 \% \mathrm{Cl} 0.22$ to 0.89 ; women $=3420 ; 1$ study; high-certainty evidence). They also have an important effect on reduction of confirmed or suspected maternal infection. The two included studies did not report on fever or urinary tract infection.

It is unclear, based on low-certainty evidence, whether prophylactic antibiotics have any impact on maternal adverse reactions (RR 2.00, $95 \% \mathrm{Cl} 0.18$ to 22.05 ; women $=2593 ; 1$ study) and maternal length of stay ( $\mathrm{MD} 0.09$ days, $95 \% \mathrm{Cl}-0.23$ to $0.41 ;$ women $=393 ; 1$ study) as the Cls were wide and included no effect. Prophylactic antibiotics slightly improve perineal pain and health consequences of perineal pain and probably reduce costs. Prophylactic antibiotics did not have an important effect on dyspareunia (difficult or painful sexual intercourse) or breastfeeding at six weeks. Antibiotic prophylaxis may slightly improve maternal hospital re-admission and maternal health-related quality of life. Neonatal adverse reactions were not reported in any included trials.

\section{Authors' conclusions}

Prophylactic intravenous antibiotics are effective in reducing infectious puerperal morbidities in terms of superficial and deep perineal wound infection or serious infectious complications in women undergoing operative vaginal deliveries without clinical indications for antibiotic administration after delivery. Prophylactic antibiotics slightly improve perineal pain and health consequences of perineal pain, probably reduce the costs, and may slightly reduce the maternal hospital re-admission and health-related quality of life. However, the effect on reduction of endometritis, organ or space perineal wound infection, maternal adverse reactions and maternal length of stay is unclear due to low-certainty evidence.

As the evidence was mainly derived from a single multi-centre study conducted in a high-income setting, future well-designed randomised trials in other settings, particularly in low- and middle-income settings, are required to confirm the effect of antibiotic prophylaxis for operative vaginal delivery.

\section{PLAIN LANGUAGE SUMMARY}

\section{Is antibiotic prophylaxis effective or safe for women undergoing operative vaginal delivery?}

We set out to assess from randomised controlled studies whether giving antibiotics to all women undergoing operative vaginal deliveries prevents infections in the mother without increasing adverse outcomes in the mother and baby. Vacuum extraction or forceps are used to deliver the baby's head in operative vaginal deliveries.

\section{What is the issue?}

Women who undergo vacuum- or forceps-assisted vaginal births may be more likely to have an infection after the birth when compared to women who experience a normal spontaneous vaginal birth. They are also more likely to be re-admitted to hospital. Women are at increased risk of infection because of the need for routine bladder catheterisation, multiple vaginal examinations, insertion of instruments into the vagina, and increased risk of vaginal deep cuts or tears during the operative birth. Infection appears as fever, infection of the uterus and surrounding tissues, an infected episiotomy or vaginal tear, or urinary tract infection. These affect the physical state of the mother and can impact on her well-being. The infection may also enter the bloodstream and affect the whole body.

\section{Why is this important?}

Vacuum extraction or forceps are used to shorten labour from the time when the cervix is fully opened to birth (second stage of labour), particularly if this is long or the baby shows signs of distress. Antibiotics can be given to mothers at the time of birth to prevent or reduce the risk of infection. However, there are still some doubts about the benefit of such antibiotics. Antibiotics can also cause adverse reactions such as rash or diarrhoea in the mother, and may be present in breast milk so that a breastfeeding baby is exposed to them.

\section{What evidence did we find?}

We updated our search for evidence from randomised controlled studies in July 2019. We included two studies, published in 1989 and 2019. The older study was conducted in the USA and the more recent study was from a number of hospital obstetric units in the UK. A total of 3813 women undergoing operative vaginal delivery were included. The USA study involved 393 women and compared $2 \mathrm{~g}$ of intravenous cefotetan after cord clamping with no treatment. The other study involved 3420 women. This study compared intravenous amoxicillin and clavulanic acid with placebo. The certainty of the evidence varied from high certainty to low, with low certainty being downgraded because of concerns relating to imprecise results, with few events and only a single study reporting on a number of the findings.

Prophylactic antibiotics given to reduce or prevent infection halved the number of women with infected episiotomies or lacerations. These findings included superficial and deep perineal wound infections (one study, 3420 women; high-certainty evidence) or wound breakdown (one study, 2593 women; moderate-certainty evidence). Serious infectious complications were also reduced (one study, 3420 women; highcertainty evidence). Due to low-certainty evidence, prophylactic antibiotics had uncertain effects on endometritis, experienced as fever and uterine tenderness or heavy bleeding (two studies, 3813 women; low-certainty evidence) and infected episiotomy/laceration presenting with organ or space perineal infection (one study, 3420 women; low-certainty evidence). 
The impact on maternal adverse reactions (one study, 2593 women; low-certainty evidence) and maternal length of stay in hospital (one study, 393 women; low-certainty evidence) was also unclear due to the low-certainty of the study. Perineal pain and health consequences of perineal pain were slightly reduced. Prophylactic antibiotics did not have a clear effect on pain during sex and breastfeeding at six weeks. Maternal hospital re-admission and maternal health-related quality of life may be slightly improved. Costs were reduced with use of prophylactic antibiotics. Neither study specifically measured fever, urinary tract infection or adverse reactions in babies.

\section{What does this mean?}

Prophylactic antibiotics into a vein are effective in reducing ill-health caused by infections in women undergoing operative vaginal deliveries, and who do not have clinical indications for antibiotic administration. The evidence was mainly from a single study in a highincome country. Well-designed randomised studies in other settings are required to confirm this finding. 


\begin{tabular}{|c|c|c|c|c|c|c|}
\hline \multicolumn{7}{|c|}{$\begin{array}{l}\text { S U M M A R Y O F F I N D I N G S } \\
\text { Summary of findings for the main comparison. Any antibiotics compared to placebo or no treatment for operative vaginal delivery }\end{array}$} \\
\hline \multicolumn{7}{|c|}{ Any antibiotics compared to placebo or no treatment for operative vaginal delivery } \\
\hline \multicolumn{7}{|c|}{$\begin{array}{l}\text { Patient or population: operative vaginal delivery } \\
\text { Setting: a hospital in USA and } 27 \text { obstetric units in UK } \\
\text { Intervention: any antibiotics } \\
\text { Comparison: placebo or no treatment }\end{array}$} \\
\hline \multirow[t]{2}{*}{ Outcomes } & \multirow{2}{*}{$\begin{array}{l}\text { Relative ef- } \\
\text { fect } \\
(95 \% \mathrm{Cl})\end{array}$} & \multicolumn{3}{|c|}{ Anticipated absolute effects ${ }^{\star}(95 \% \mathrm{Cl})$} & \multirow{2}{*}{$\begin{array}{l}\text { Certainty of } \\
\text { the evidence } \\
\text { (GRADE) }\end{array}$} & \multirow{2}{*}{$\begin{array}{l}\text { What hap- } \\
\text { pens }\end{array}$} \\
\hline & & $\begin{array}{l}\text { Withol } \\
\text { antibic }\end{array}$ & With any ar & Difference & & \\
\hline Fever - not measured & - & - & - & & - & $\begin{array}{l}\text { This outcome } \\
\text { was not re- } \\
\text { ported in the } \\
2 \text { included } \\
\text { studies. }\end{array}$ \\
\hline \multirow{2}{*}{$\begin{array}{l}\text { Infected episiotomy/laceration (superficial } \\
\text { perineal wound infection) } \\
\text { № of participants: } 3420 \\
\text { (1 RCT) }\end{array}$} & \multirow{2}{*}{$\begin{array}{l}\text { RR } 0.53 \\
\text { ( } 0.40 \text { to } 0.69)\end{array}$} & \multicolumn{3}{|c|}{ Study population } & \multirow{2}{*}{$\begin{array}{l}\oplus \oplus \oplus \oplus \\
\mathrm{HIGH}\end{array}$} & \\
\hline & & $8.3 \%$ & $\begin{array}{l}4.4 \% \\
\text { (3.3 to } 5.7 \text { ) }\end{array}$ & $\begin{array}{l}3.9 \% \text { fewer } \\
\text { ( } 5 \text { fewer to } 2.6 \text { fewer) }\end{array}$ & & \\
\hline \multirow{2}{*}{$\begin{array}{l}\text { Infected episiotomy/laceration (deep per- } \\
\text { ineal wound infection } \\
\text { № of participants: } 3420 \\
\text { (1 RCT) }\end{array}$} & \multirow{2}{*}{$\begin{array}{l}\text { RR } 0.46 \\
(0.31 \text { to } 0.69)\end{array}$} & \multicolumn{3}{|c|}{ Study population } & \multirow{2}{*}{$\begin{array}{l}\oplus \oplus \oplus \oplus \\
\mathrm{HIGH}\end{array}$} & \\
\hline & & $4.5 \%$ & $\begin{array}{l}2.1 \% \\
(1.4 \text { to } 3.1)\end{array}$ & $\begin{array}{l}2.4 \% \text { fewer } \\
\text { (3.1 fewer to } 1.4 \text { fewer) }\end{array}$ & & \\
\hline \multirow{2}{*}{$\begin{array}{l}\text { Infected episiotomy/laceration (organ or } \\
\text { space infection) } \\
\text { № of participants: } 3420 \\
\text { (1 RCT) }\end{array}$} & \multirow{2}{*}{$\begin{array}{l}\text { RR } 0.11 \\
\text { (0.01 to } 2.05)\end{array}$} & \multicolumn{3}{|c|}{ Study population } & \multirow{2}{*}{$\begin{array}{l}\oplus \oplus \ominus \ominus \\
\text { LOW } 1\end{array}$} & \\
\hline & & $0.2 \%$ & $\begin{array}{l}0.0 \% \\
(0 \text { to } 0.5)\end{array}$ & $\begin{array}{l}0.2 \% \text { fewer } \\
\text { ( } 0.2 \text { fewer to } 0.2 \text { more) }\end{array}$ & & \\
\hline \multirow{2}{*}{$\begin{array}{l}\text { Infected episiotomy/laceration (wound } \\
\text { breakdown) } \\
\text { № of participants: } 2593 \\
\text { (1 RCT) }\end{array}$} & \multirow{2}{*}{$\begin{array}{l}\text { RR } 0.52 \\
\text { (0.43 to } 0.63 \text { ) }\end{array}$} & \multicolumn{3}{|c|}{ Study population } & \multirow{2}{*}{$\begin{array}{l}\oplus \oplus \oplus \ominus \\
\text { MODERATE } 2\end{array}$} & \\
\hline & & $21.0 \%$ & $\begin{array}{l}10.9 \% \\
\text { (9 to } 13.2 \text { ) }\end{array}$ & $\begin{array}{l}10.1 \% \text { fewer } \\
\text { (12 fewer to } 7.8 \text { fewer) }\end{array}$ & & \\
\hline $\begin{array}{l}\text { Endometritis } \\
\text { № of participants: } 3813\end{array}$ & $\begin{array}{l}\text { RR } 0.32 \\
\text { (0.04 to } 2.64)\end{array}$ & \multicolumn{3}{|c|}{ Study population } & $\begin{array}{l}\oplus \oplus \ominus \ominus \\
\text { LOW } 34\end{array}$ & \\
\hline
\end{tabular}

Comparison: placebo or no treatment 


\begin{tabular}{|c|c|c|c|c|c|c|}
\hline \multirow{2}{*}{ 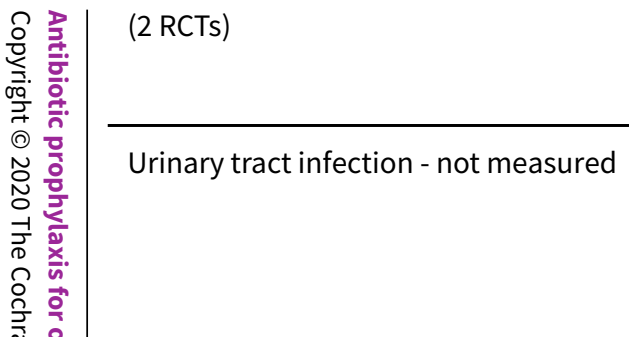 } & & \multirow{2}{*}{$\begin{array}{l}1.6 \% \\
-\end{array}$} & $\begin{array}{l}0.5 \% \\
(0.1 \text { to } 4.2)\end{array}$ & \multicolumn{2}{|l|}{$\begin{array}{l}1.1 \% \text { fewer } \\
\text { ( } 1.5 \text { fewer to } 2.6 \text { more) }\end{array}$} & \multirow[b]{2}{*}{$\begin{array}{l}\text { This outcome } \\
\text { was not re- } \\
\text { ported in the } \\
2 \text { included } \\
\text { studies. }\end{array}$} \\
\hline & - & & - & & - & \\
\hline Serious infectious complications & RR 0.44 & \multicolumn{3}{|c|}{ Study population } & \multirow{2}{*}{$\begin{array}{l}\oplus \oplus \oplus \oplus \\
\mathrm{HIGH}\end{array}$} & \\
\hline$(1 \mathrm{RCT})$ & & $1.5 \%$ & $\begin{array}{l}0.6 \% \\
(0.3 \text { to } 1.3)\end{array}$ & $\begin{array}{l}0.8 \% \text { fewer } \\
\text { ( } 1.1 \text { fewer to } 0.2 \text { fewer) }\end{array}$ & & \\
\hline \multirow{2}{*}{$\begin{array}{l}\text { Maternal adverse reactions } \\
\text { № of participants: } 2593 \\
(1 \mathrm{RCT})\end{array}$} & RR 2.00 & \multicolumn{3}{|c|}{ Study population } & \multirow{2}{*}{$\begin{array}{l}\oplus \oplus \ominus \ominus \\
\text { LOW } 1\end{array}$} & \\
\hline & 22.05) & $0.1 \%$ & $\begin{array}{l}0.2 \% \\
(0 \text { to } 1.7)\end{array}$ & $\begin{array}{l}0.1 \% \text { more } \\
\text { ( } 0.1 \text { fewer to } 1.6 \text { more) }\end{array}$ & & \\
\hline $\begin{array}{l}\text { Maternal length of stay } \\
\text { № of participants: } 393 \\
(1 \mathrm{RCT})\end{array}$ & - & $\begin{array}{l}\text { The mean ma- } \\
\text { ternal length } \\
\text { of stay with- } \\
\text { out any an- } \\
\text { tibiotics was } \\
2.37 \text { days. }\end{array}$ & $\begin{array}{l}\text { The mean maternal } \\
\text { length of stay with an- } \\
\text { tibiotics was } 0.09 \text { days } \\
\text { more ( } 0.23 \text { days less to } \\
0.41 \text { days more) }\end{array}$ & & $\begin{array}{l}\oplus \oplus \odot \ominus \\
\text { LOW } 5\end{array}$ & \\
\hline
\end{tabular}

${ }^{\star}$ The risk in the intervention group (and its $95 \%$ confidence interval) is based on the assumed risk in the comparison group and the relative effect of the intervention (and its $95 \% \mathrm{Cl}$ ).

Cl: Confidence interval; RR: Risk ratio

\section{GRADE Working Group grades of evidence}

High certainty: we are very confident that the true effect lies close to that of the estimate of the effect.

Moderate certainty: we are moderately confident in the effect estimate; the true effect is likely to be close to the estimate of the effect, but there is a possibility that it is substantially different.

Low certainty: our confidence in the effect estimate is limited; the true effect may be substantially different from the estimate of the effect.

Very low certainty: we have very little confidence in the effect estimate; the true effect is likely to be substantially different from the estimate of effect.

1 We downgraded (2) levels for very serious imprecision due to wide confidence interval crossing the line of no effect and small number of events.

2 We downgraded (1) level for serious limitation in study design due to loss to follow up for this outcome higher than $20 \%$.

3 We downgraded (1) level for serious inconsistency due to unexplained substantial heterogeneity.

4 We downgraded (1) level for serious imprecision due to wide confidence interval.

5 We downgraded (1) level for serious limitations in study design due to many domains being at unclear risk of bias. 


\section{B A C K G R O U N D}

\section{Description of the condition}

Operative vaginal delivery is the term used to describe delivery of the fetal head assisted by either vacuum extractor or forceps. The commonest indications for operative vaginal delivery are prolonged second stage of labour, suspicion of immediate or potential fetal compromise and shortening of the second stage of labour for maternal benefit (RCOG 2011; ACOG 2015). The rates of operative vaginal delivery reported vary by centres in different countries (Cammu 2011; Hanley 2010; Hehir 2013; Janni 2002; Kabiru 2001; Lawani 2014; Mola 2011; Walsh 2013) with ranges from $2.1 \%$ in Papua NewGuinea (Mola 2011) to $19.2 \%$ of all births in northern Belgium (Cammu 2011).

The risk of postpartum infection is increased after operative vaginal birth because of higher rates of vaginal lacerations, routine bladder catheterisation, multiple vaginal examinations, insertion of instruments into the vagina and contamination (Chaim 2000; Pranchev 1993). Instrumental deliveries require additional vaginal examinations, a known risk factor for endometritis and febrile morbidity (ACOG 2015; Chang 1992; Dare 1998). Insertion of instruments and contamination is also assumed to be one of the risks of postpartum infection because of difficulties in adhering to aseptic practices during delivery (Dare 1998).

\section{Description of the intervention}

Antibiotic prophylaxis is one of the methods used to reduce the risk of postpartum infections. It has been widely studied in obstetrics and has shown to be effective in reducing postoperative puerperal morbidity after caesarean section in a Cochrane Review (Smail 2014). However, there are still some doubts about the benefit of prophylactic antibiotics in reducing postpartum infection after operative vaginal delivery. Due to the physiological change of gastric emptying time, plasma volume and renal function during pregnancy, the pharmacokinetics of antibiotics differ between pregnant and nonpregnant women. For these reasons careful consideration needs to be given to the types of antibiotics and antibiotic regimens given to pregnant women for prophylactic use (ACOG 2018).

\section{How the intervention might work}

The reported incidence of postpartum infection or endometritis after operative vaginal delivery in studies varies from $3.5 \%$ to $16 \%$ (Hagadorn-Freathy 1991; Heitmann 1989; Kabiru 2001; Williams 1991). In addition, the outcomes of readmission within 60 days after delivery and maternal sepsis have been reported as increased in incidence following the use of operative vaginal delivery in comparison with spontaneous vaginal delivery (Acosta 2014; Liu 2005). Postpartum infection not only affects the physical status of the mother and prolongs hospital stay after birth, but also significantly impacts on the psychological well-being of the mother (RCOG 2011).

The most common micro-organisms in the genitourinary tract causing postpartum morbidities such as fever, endometritis, infected episiotomy/vaginal laceration or urinary tract infection are Enterococci, Streptococci, Staphylococci, Gram-negative bacilli and anaerobes (Kok 2000; Stray-Pedersen 1988). Group B streptococcus, Enterococcus, Gardnerella vaginalis, Staphylococcus aureus and anaerobe bacteria were usually recovered from the cervix and endometrium among febrile postpartum women (Eschenbach 1986). The types of antibiotics selected to be prophylactically used should be effective against these common micro-organisms and include the following: ampicillin, cephazolin, clindamycin, vancomycin, azithromycin, and the aminoglycosides (ACOG 2018).

\section{Why it is important to do this review}

Previous studies (Janisch 1979; Rechlin 1988) have indicated that prophylactic antibiotics may not be necessary due to the relatively low risk of infectious morbidity, and uncertain effect on puerperal fever. Aseptic precautions during operative vaginal delivery may be enough to prevent postpartum infection (Janisch 1979). In contrast, other studies did suggest that antibiotic prophylaxis might reduce the risk of infection after normal vaginal delivery and operative vaginal delivery (Fernandez 1993; Heitmann 1989). Criscuolo 1990 suggested that the cost of prophylactic antibiotics could be much lower compared with the cost of treating the complications of infection related to procedures during delivery.

However, widespread use of antibiotics may contribute to the development of antibiotic-resistant bacteria (Towers 1998; Weinstein 1996). A study in Vietnam found that $98 \%$ of women who gave birth vaginally received antibiotics (Ngoc 2005). The recently reported resistance patterns of isolated strains of Escherichia coli, Staphylococcus aureus, Enterococci, and Streptococcus pneumoniae are concerning (ACOG 2018). In addition, antibiotics may contaminate breast milk, as well as cause adverse reactions such as rash or antibiotic-related diarrhoea (Dancer 2004).

There is also a concern that there may be a significantly increased risk of third- or fourth-degree tears, severe maternal morbidity and death, perinatal mortality and neonatal mortality in women with operative vaginal birth compared with normal birth (Angioli 2000; Lumbiganon 2010). The incidence of third- and fourth-degree tears reported range from $1 \%$ to $36 \%$ of all births (Boucoiran 2010; Goldberg 2003; Johnson 2004; Nkwabong 2011; Panigrahy 2008; Prapas 2009). The rate of perineal wound complication measured at two weeks postpartum was found to be significantly lower with the use of antibiotic prophylaxis; however, loss to follow-up was high and thus these results should be interpreted with caution (Buppasiri 2014; Duggal 2008).

Therefore, the effectiveness of antibiotic prophylaxis for operative vaginal delivery needs to be carefully evaluated. This is an update of a review last published in 2017.

\section{O B J E C T IVES}

To assess the effectiveness and safety of antibiotic prophylaxis in reducing infectious puerperal morbidities in women undergoing operative vaginal deliveries including vacuum or forceps delivery, or both.

\section{METHODS}

\section{Criteria for considering studies for this review}

\section{Types of studies}

All randomised trials comparing any prophylactic antibiotic regimens with placebo or no treatment in women undergoing vacuum or forceps delivery. Cluster-trials were eligible for inclusion 
as were trials presented as an Abstract if sufficient information was reported in order to assess eligibility. Quasi-randomised and crossover trials were not eligible for inclusion.

\section{Types of participants}

Pregnant women without evidence of infections or other indications for antibiotics of any gestational age undergoing vacuum or forceps delivery for any indication.

\section{Types of interventions}

Any antibiotic prophylaxis (any dosage regimen, any route of administration or at any time during delivery or puerperium) compared with either placebo or no treatment.

\section{Types of outcome measures}

We considered the following clinical outcomes.

\section{Primary outcomes}

1. Fever (body temperature of 38 degrees celsius or higher) occurring on any two occasions in the first 10 days postpartum, exclusive of the first 24 hours

2. Infected episiotomy/perineal/vaginal laceration (oedematous, erythematous, wound edge with pain, serosanguineous or frankly purulent material or wound dehiscence)

3. Endometritis (fever and uterine tenderness or heavy bleeding)

4. Urinary tract infection (fever or dysuria and positive urine culture)

5. Serious infectious complications (such as bacteraemia, systemic infection, septic shock, septic thrombophlebitis, necrotising fasciitis or death attributed to infection)

6. Confirmed or suspected maternal infection within six weeks of delivery, defined by a new prescription of antibiotics for presumed perineal wound-related infection, endometritis or uterine infection, urinary tract infection with systemic features or infection; confirmed systemic infection on culture; or endometritis (non-prespecified)

\section{Secondary outcomes}

1. Maternal adverse reactions such as allergic reactions, anaphylaxis, antibiotic-associated diarrhoea

2. Maternal length of stay

3. Perineal pain (non-prespecified)

4. Use of pain relief for perineal pain (non-prespecified)

5. Need for additional perineal care (non-prespecified)

6. Dyspareunia (difficult or painful sexual intercourse) (nonprespecified)

7. Breastfeeding at six weeks (non-prespecified)

8. Perineum "ever too painful or uncomfortable" to feed baby (non-prespecified)

9. Any primary care or home visits in relation to perineum (nonprespecified)

10.Any outpatient visit in relation to perineum (non-prespecified)

11.Maternal hospital re-admission (non-prespecified)

12. Maternal health-related quality of life (non-prespecified)

13. Costs

14. Neonatal adverse reactions such as such as jaundice, early neonatal infection, or any infant outcomes reported

\section{Search methods for identification of studies}

The following methods section of this review was based on a standard template used by Cochrane Pregnancy and Childbirth.

\section{Electronic searches}

For this update, we searched Cochrane Pregnancy and Childbirth's Trials Register by contacting their Information Specialist (5 July 2019).

The Register is a database containing over 25,000 reports of controlled trials in the field of pregnancy and childbirth. It represents over 30 years of searching. For full current search methods used to populate Pregnancy and Childbirth's Trials Register including the detailed search strategies for CENTRAL, MEDLINE, Embase and CINAHL; the list of handsearched journals and conference proceedings, and the list of journals reviewed via the current awareness service, please follow this link.

Briefly, Cochrane Pregnancy and Childbirth's Trials Register is maintained by their Information Specialist and contains trials identified from:

1. monthly searches of the Cochrane Central Register of Controlled Trials (CENTRAL);

2. weekly searches of MEDLINE (Ovid);

3. weekly searches of Embase (Ovid);

4. monthly searches of CINAHL (EBSCO);

5. handsearches of 30 journals and the proceedings of major conferences;

6. weekly current awareness alerts for a further 44 journals plus monthly BioMed Central email alerts.

Search results are screened by two people and the full text of all relevant trial reports identified through the searching activities described above is reviewed. Based on the intervention described, each trial report is assigned a number that corresponds to a specific Pregnancy and Childbirth review topic (or topics), and is then added to the Register. The Information Specialist searches the Register for each review using this topic number rather than keywords. This results in a more specific search set that has been fully accounted for in the relevant review sections (Included studies; Excluded studies).

In addition, we searched ClinicalTrials.gov and the WHO International Clinical Trials Registry Platform (ICTRP) for unpublished, planned and ongoing trial reports (5 July 2019) using the search methods detailed in Appendix 1.

\section{Searching other resources}

We searched the reference lists of retrieved studies.

We did not apply any language or date restrictions.

\section{Data collection and analysis}

For methods used in the previous version of this review, see Liabsuetrakul 2017.

For this update, we used the following methods. The methods section of this review is based on a standard template used by Cochrane Pregnancy and Childbirth. 


\section{Selection of studies}

Two review authors independently assessed for inclusion all the potential studies identified as a result of the search strategy. We resolved any disagreement through discussion or, if required, we consulted the third review author.

\section{Data extraction and management}

We designed a form to extract data. For eligible studies, two review authors extracted the data using the agreed form. We resolved discrepancies through discussion or, if required, we consulted the third review author. Data were entered into Review Manager software (RevMan 2014) and checked for accuracy.

When information regarding any of the above was unclear, we planned to contact authors of the original reports to provide further details.

\section{Assessment of risk of bias in included studies}

Two review authors independently assessed risk of bias for each study using the criteria outlined in the Cochrane Handbook for Systematic Reviews of Interventions (Higgins 2011). Any disagreement was resolved by discussion or by involving a third assessor.

\section{(1) Random sequence generation (checking for possible selection bias)}

We described for the two included studies the method used to generate the allocation sequence in sufficient detail to allow an assessment of whether it should produce comparable groups.

We assessed the method as:

- low risk of bias (any truly random process, e.g. random number table; computer random number generator);

- high risk of bias (any non-random process, e.g. odd or even date of birth; hospital or clinic record number);

- unclear risk of bias.

\section{(2) Allocation concealment (checking for possible selection bias)}

We described for the two included studies the method used to conceal allocation to interventions prior to assignment and assessed whether intervention allocation could have been foreseen in advance of, or during recruitment, or changed after assignment.

We assessed the methods as:

- low risk of bias (e.g. telephone or central randomisation; consecutively numbered sealed opaque envelopes);

- high risk of bias (open random allocation; unsealed or nonopaque envelopes, alternation; date of birth);

- unclear risk of bias.

\section{(3.1) Blinding of participants and personnel (checking for possible performance bias)}

We described for the included studies the methods used, if any, to blind study participants and personnel from knowledge of which intervention a participant received. We considered in advance that studies would be at low risk of bias if they were blinded, or if we judged that the lack of blinding unlikely to affect results. We assessed blinding separately for different outcomes or classes of outcomes.

We assessed the methods as:

- low, high or unclear risk of bias for participants;

- low, high or unclear risk of bias for personnel.

\section{(3.2) Blinding of outcome assessment (checking for possible detection bias)}

We described for the included studies the methods used, if any, to blind outcome assessors from knowledge of which intervention a participant received. We assessed blinding separately for different outcomes or classes of outcomes.

We assessed methods used to blind outcome assessment as:

- low, high or unclear risk of bias.

(4) Incomplete outcome data (checking for possible attrition bias due to the amount, nature and handling of incomplete outcome data)

We described for the two included studies, and for each outcome or class of outcomes, the completeness of data including attrition and exclusions from the analysis. We stated whether attrition and exclusions were reported and the numbers included in the analysis at each stage (compared with the total randomised participants), reasons for attrition or exclusion where reported, and whether missing data were balanced across groups or were related to outcomes. Where sufficient information was reported, or could be supplied by the trial authors, we planned to re-include missing data in the analyses which we undertook.

We assessed methods as:

- low risk of bias (e.g. no missing outcome data; missing outcome data balanced across groups);

- high risk of bias (e.g. numbers or reasons for missing data imbalanced across groups; 'as treated' analysis done with substantial departure of intervention received from that assigned at randomisation);

- unclear risk of bias.

\section{(5) Selective reporting (checking for reporting bias)}

We described for both included studies how we investigated the possibility of selective outcome reporting bias and what we found.

We assessed the methods as:

- low risk of bias (where it is clear that all of the studies' prespecified outcomes and all expected outcomes of interest to the review have been reported);

- high risk of bias (where not all the studies' pre-specified outcomes have been reported; one or more reported primary outcomes were not pre-specified; outcomes of interest are reported incompletely and so cannot be used; study fails to include results of a key outcome that would have been expected to have been reported);

- unclear risk of bias. 
(6) Other bias (checking for bias due to problems not covered by (1) to (5) above)

We described for both included studies any important concerns we had about other possible sources of bias.

\section{(7) Overall risk of bias}

We made explicit judgements about whether the included studies were at high risk of bias, according to the criteria given in the Handbook (Higgins 2011). With reference to (1) to (6) above, we planned to assess the likely magnitude and direction of the bias and whether we considered it is likely to impact on the findings. In future updates, if more studies are included, we will explore the impact of the level of bias through undertaking sensitivity analyses - see Sensitivity analysis.

\section{Assessment of the certainty of the evidence using the GRADE approach}

We assessed the certainty of the evidence using the GRADE approach as outlined in the GRADE handbook in order to assess the certainty of the body of evidence relating to the following outcomes for the main comparison between any antibiotic prophylaxis (any dosage regimen, any route of administration or at any time during delivery or puerperium) compared with either placebo or no treatment.

1. Fever (body temperature of 38 degrees celsius or higher) occurring on any two occasions in the first 10 days postpartum, exclusive of the first 24 hours

2. Infected episiotomy/perineal/vaginal laceration (oedematous, erythematous, wound edge with pain, serosanguineous or frankly purulent material or wound dehiscence)

3. Endometritis (fever and uterine tenderness or heavy bleeding)

4. Urinary tract infection (fever or dysuria and positive urine culture)

5. Serious infectious complications (such as bacteraemia, septic shock, septic thrombophlebitis, necrotising fasciitis or death attributed to infection)

6. Maternal adverse reactions such as allergic reactions, anaphylaxis, antibiotic-associated diarrhoea

7. Maternal length of stay

We used the GRADEpro Guideline Development Tool to import data from Review Manager 5.3 (RevMan 2014) in order to create a 'Summary of findings' table. A summary of the intervention effect and a measure of certainty for each of the above outcomes was produced using the GRADE approach. The GRADE approach uses five considerations (study limitations, consistency of effect, imprecision, indirectness and publication bias) to assess the certainty of the body of evidence for each outcome. The evidence can be downgraded from 'high certainty' by one level for serious (or by two levels for very serious) limitations, depending on assessments for risk of bias, indirectness of evidence, serious inconsistency, imprecision of effect estimates or potential publication bias.

\section{Measures of treatment effect}

\section{Dichotomous data}

For dichotomous data, we presented results as summary risk ratio with $95 \%$ confidence intervals.

\section{Continuous data}

We used the mean difference if outcomes were measured in the same way between trials. We planned to use the standardised mean difference to combine trials that measured the same outcome, but used different methods.

\section{Unit of analysis issues}

\section{Cluster-randomised trials}

In future updates, if cluster-randomised trials are identified and included, we will adjust the standard errors using the methods described in the Handbook using an estimate of the intracluster correlation co-efficient (ICC) derived from the trial (if possible), from a similar trial or from a study of a similar population. If we use ICCs from other sources, we will report this and conduct sensitivity analyses to investigate the effect of variation in the ICC.

If we identify both cluster-randomised trials and individuallyrandomised trials, we plan to synthesise the relevant information. We will consider it reasonable to combine the results from both if there is little heterogeneity between the study designs and the interaction between the effect of intervention and the choice of randomisation unit is considered to be unlikely.

We will also acknowledge heterogeneity in the randomisation unit and perform a sensitivity analysis to investigate the effects of the randomisation unit.

\section{Cross-over trials}

This study design not applicable for this review.

\section{Other unit of analysis issues}

Not applicable.

\section{Dealing with missing data}

For included studies, we noted levels of attrition. In future updates, if more eligible studies are included, the impact of including studies with high levels of missing data in the overall assessment of treatment effect will be explored by using sensitivity analysis.

For all outcomes, analyses were carried out, as far as possible, on an intention-to-treat basis, i.e. we attempted to include all participants randomised to each group in the analyses. The denominator for each outcome in the included study was the number randomised minus any participants whose outcomes were known to be missing.

\section{Assessment of heterogeneity}

We assessed statistical heterogeneity in each meta-analysis using the $\mathrm{Tau}^{2}, \mathrm{I}^{2}$ and $\mathrm{Chi}^{2}$ statistics. We regarded heterogeneity as substantial if an $\mathrm{I}^{2}$ was greater than $30 \%$ and either a $\mathrm{Tau}^{2}$ was greater than zero, or there was a low $P$ value (less than 0.10 ) in the $\mathrm{Chi}^{2}$ test for heterogeneity. If we identified substantial heterogeneity (above 30\%), we planned to explore it by prespecified subgroup analysis. If any outcome includes only one study, the test for heterogeneity is not applicable.

\section{Assessment of reporting biases}

In future updates, if there are 10 or more studies in the metaanalysis we will investigate reporting biases (such as publication 
bias) using funnel plots. We will assess funnel plot asymmetry visually. If asymmetry is suggested by a visual assessment, we will perform exploratory analyses to investigate it.

\section{Data synthesis}

We carried out statistical analysis using the Review Manager software (RevMan 2014). We used fixed-effect meta-analysis for combining data where it is reasonable to assume that studies are estimating the same underlying treatment effect: i.e. where trials are examining the same intervention, and the trials' populations and methods are judged sufficiently similar.

When substantial statistical heterogeneity was detected, we considered whether the clinical or methodological heterogeneity was influenced using subgroup or sensitivity analyses and we used random-effects meta-analysis to produce an overall summary, if an average treatment effect across trials is considered clinically meaningful. The random-effects summary was treated and presented as the average of the range of treatment effects with 95\% confidence intervals, and the estimates of $\operatorname{Tau}^{2}$ and $\mathrm{I}^{2}$.

\section{Subgroup analysis and investigation of heterogeneity}

We planned to investigate the substantial heterogeneity due to different clinical characteristics among included studies using subgroup analysis, if appropriate.
In future updates, we will carry out the following subgroup analyses for primary outcomes.

1. Vacuum or forceps deliveries

2. Different antibiotic regimens

We will assess subgroup differences by interaction tests available within RevMan (RevMan 2014). We will report the results of subgroup analyses quoting the $\mathrm{Chi}^{2}$ statistic and $\mathrm{P}$ value, and the interaction test $I^{2}$ value.

\section{Sensitivity analysis}

We planned to carry out sensitivity analyses to explore the effect of trial quality assessed by concealment of allocation, high attrition rates, or both, with poor-quality studies being excluded from the analyses in order to assess whether this makes any difference to the overall result.

\section{RESULTS}

\section{Description of studies}

Results of the search

See: Figure 1. 
Figure 1. Study flow diagram.

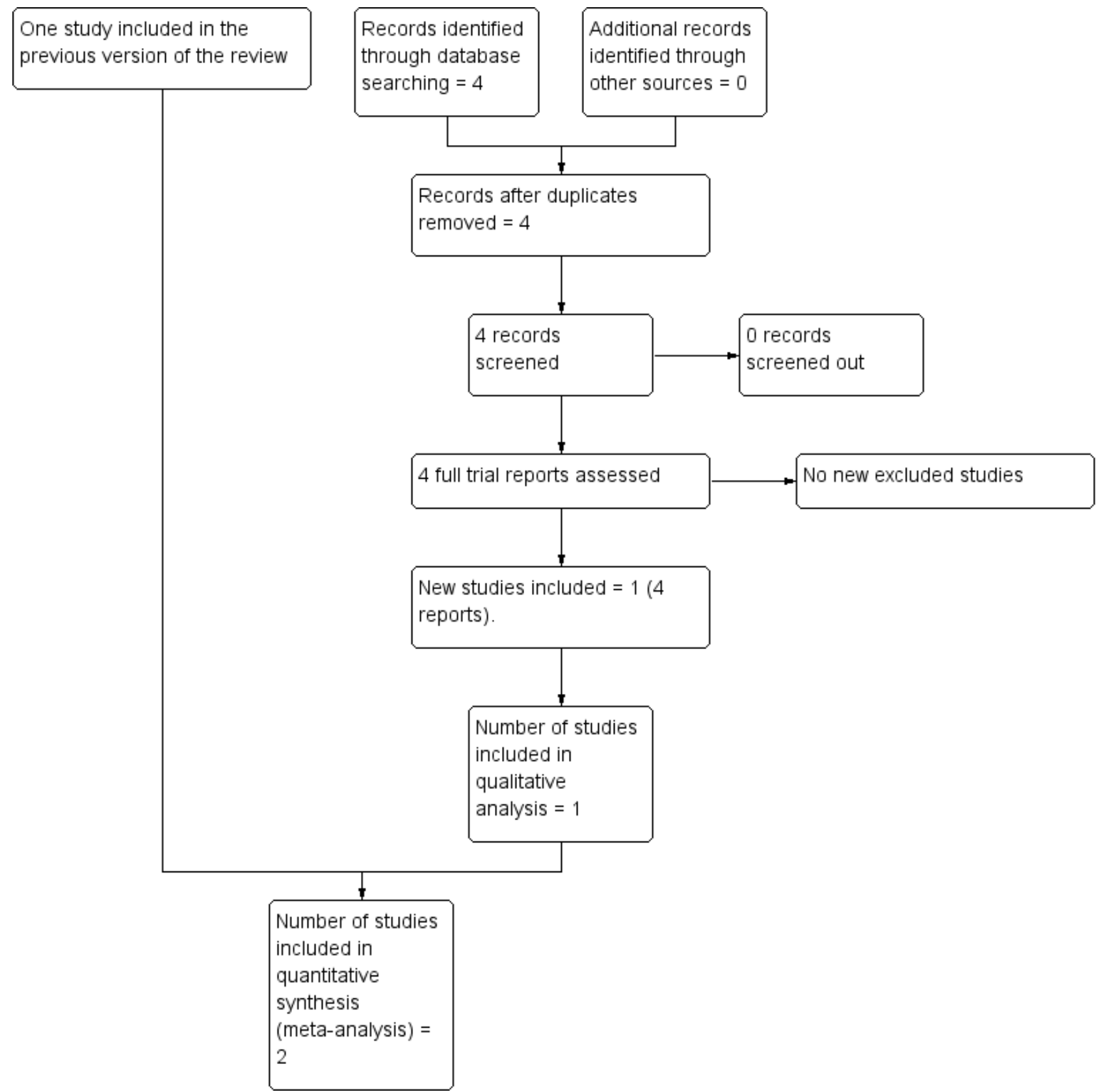

This review update includes two studies (ANODE 2019; Heitmann 1989). One of these (Heitmann 1989) was included in the previous version of this review (Liabsuetrakul 2017). For this update, we identified three new reports that were assessed, together with a report of an ongoing study that had been awaiting classification in the previous version of this review. All four reports relate to a new trial, which has been included in this update (ANODE 2019).

\section{Included studies}

We included two studies involving a total of 3813 women, 393 women in one study (Heitmann 1989) and 3420 women in another study (ANODE 2019). A total of seven women withdrew consent before the intervention was given comparing prophylactic

Antibiotic prophylaxis for operative vaginal delivery (Review)

Copyright $\odot 2020$ The Cochrane Collaboration. Published by John Wiley \& Sons, Ltd. antibiotics in women undergoing operative vaginal deliveries with placebo or no antibiotics (ANODE 2019).

\section{(1) Study location and settings}

One study was conducted in USA (Heitmann 1989), and the other study was conducted in 27 hospital obstetric units in the UK (ANODE 2019).

\section{(2) Participants}

A total of 3813 women in two included studies involving 1907 women undergoing operative vaginal delivery received prophylactic antibiotics versus 1906 women with no treatment or placebo. One trial involved 393 women, of which $43.2 \%$ delivered by forceps and $56.8 \%$ by vacuum extraction (Heitmann 1989). The 
other trial involved 3420 women. of which 20 sets of twins were included leading to a total of 3440 births, delivered by forceps in $2234(65 \%)$ and vacuum extraction in $1196(35 \%)$, but it was noted that less than $1 \%(10)$ were by spontaneous vaginal delivery (ANODE 2019).

\section{(3) Interventions}

One study (Heitmann 1989) compared $2 \mathrm{~g}$ of intravenous cefotetan after cord clamping $(n=192)$ with no treatment $(n=201)$. The other study (ANODE 2019) compared intravenous amoxicillin and clavulanic acid (1 g amoxicillin and $200 \mathrm{mg}$ clavulanic acid) as soon as possible and no more than six hours after giving birth $(n=1715)$ with placebo using $20 \mathrm{~mL}$ of intravenous sterile $0.9 \%$ saline within the same timeframe $(n=1705)$.

\section{(4) Outcomes}

One study reported the outcomes of endomyometritis and maternal length of stay (Heitmann 1989). The other study (ANODE 2019) measured confirmed or suspected maternal infection, confirmed systemic infection on culture or endometritis as primary outcomes, and systemic sepsis, perineal wound infection, perineal pain, use of pain relief, hospital bed stay until discharge, need for additional perineal care, dyspareunia, breastfeeding at six weeks, perineum "ever too painful or uncomfortable" to feed baby, maternal health-related quality of life, breastfeeding, wound breakdown, intervention side-effects, healthcare resource use and costs, or adverse events as secondary outcomes. Perineal wound infections in terms of superficial incisional infection, deep incisional infection, or organ or space infection and wound breakdown were reported in ANODE 2019, which were considered as the infected episiotomy/perineal/vaginal laceration in this review. The measurement or scale used to assess perineal pain and perineum "ever too painful or uncomfortable" to feed baby was not described in the trial. However, in the trial protocol (Knight 2018), it was mentioned that pain was measured by the standard questions developed for the HOOP study (McCandlish 1998) and the PREVIEW study (Dudley 2017) where pain was rated as none/mild/moderate/ severe.

The definitions of endomyometritis in Heitmann 1989 were as same as that of endometritis in ANODE 2019. Both studies did not specifically measure fever, urinary tract infection (fever or dysuria and positive urine culture) or neonatal adverse reactions.

\section{(5) Dates of study, funding sources and declarations of interest}

Dates when the studies were conducted were reported as: September 1986 to February 1989 (Heitmann 1989) and 13 March 2016 to 13 June 2018 (ANODE 2019).

Funding sources and declarations of interest among primary researchers were reported in one included study (ANODE 2019) and could not be identified in the other included study (Heitmann 1989).

For details of the two included trials, see the Characteristics of included studies table.

\section{Excluded studies}

One study was excluded (De Meeus 1991). The study was only available as an abstract and there was insufficient information in order to assess fully for eligibility. We had contacted the authors for further information. For further details of the excluded study, see the Characteristics of excluded studies table.

\section{Risk of bias in included studies}

According to the 'Risk of bias' tool, one study had unclear risk of bias overall (Heitmann 1989) and another study showed a low risk of bias overall (ANODE 2019).

Details of the two included studies are in the Characteristics of included studies table. Each risk of bias domain in summarised in Figure 2 and Figure 3.

\section{Figure 2. 'Risk of bias' graph: review authors' judgements about each risk of bias item presented as percentages} across all included studies.

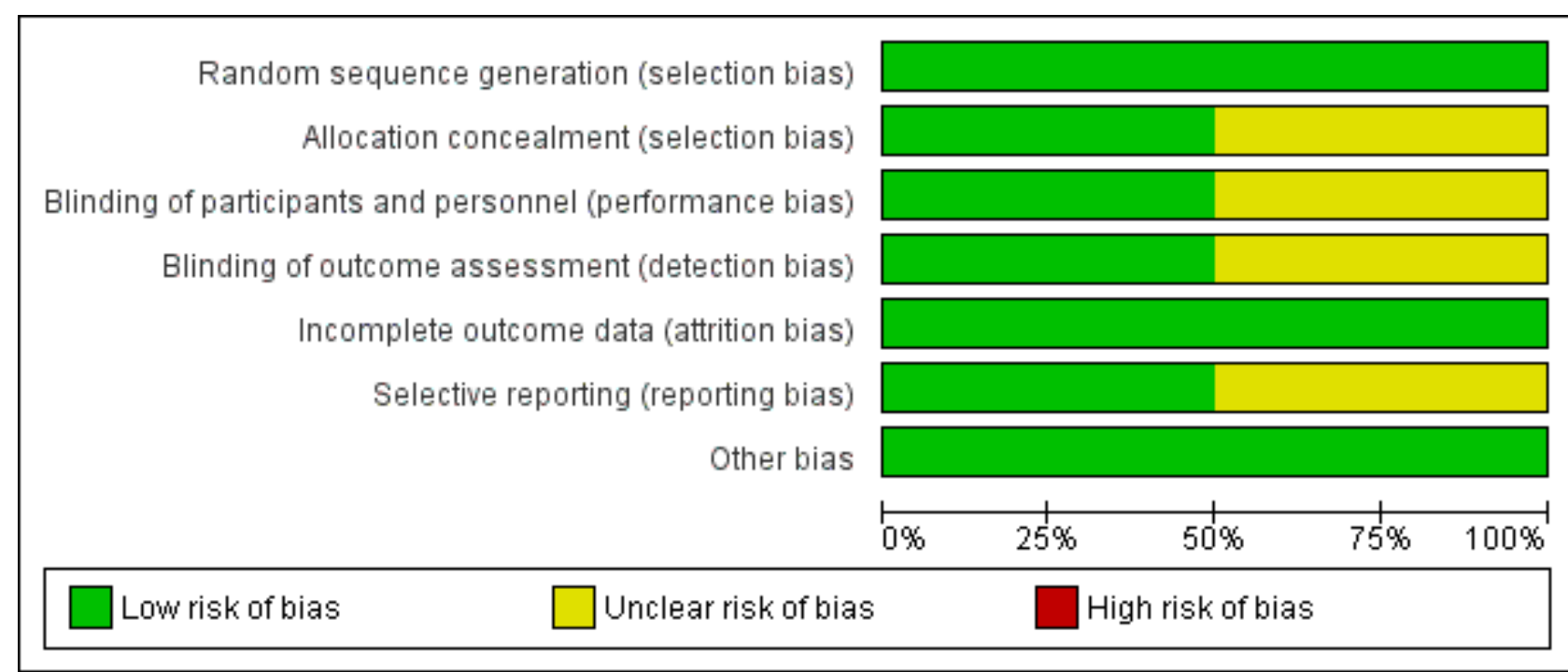


Figure 3. 'Risk of bias' summary: review authors' judgements about each risk of bias item for each included study.

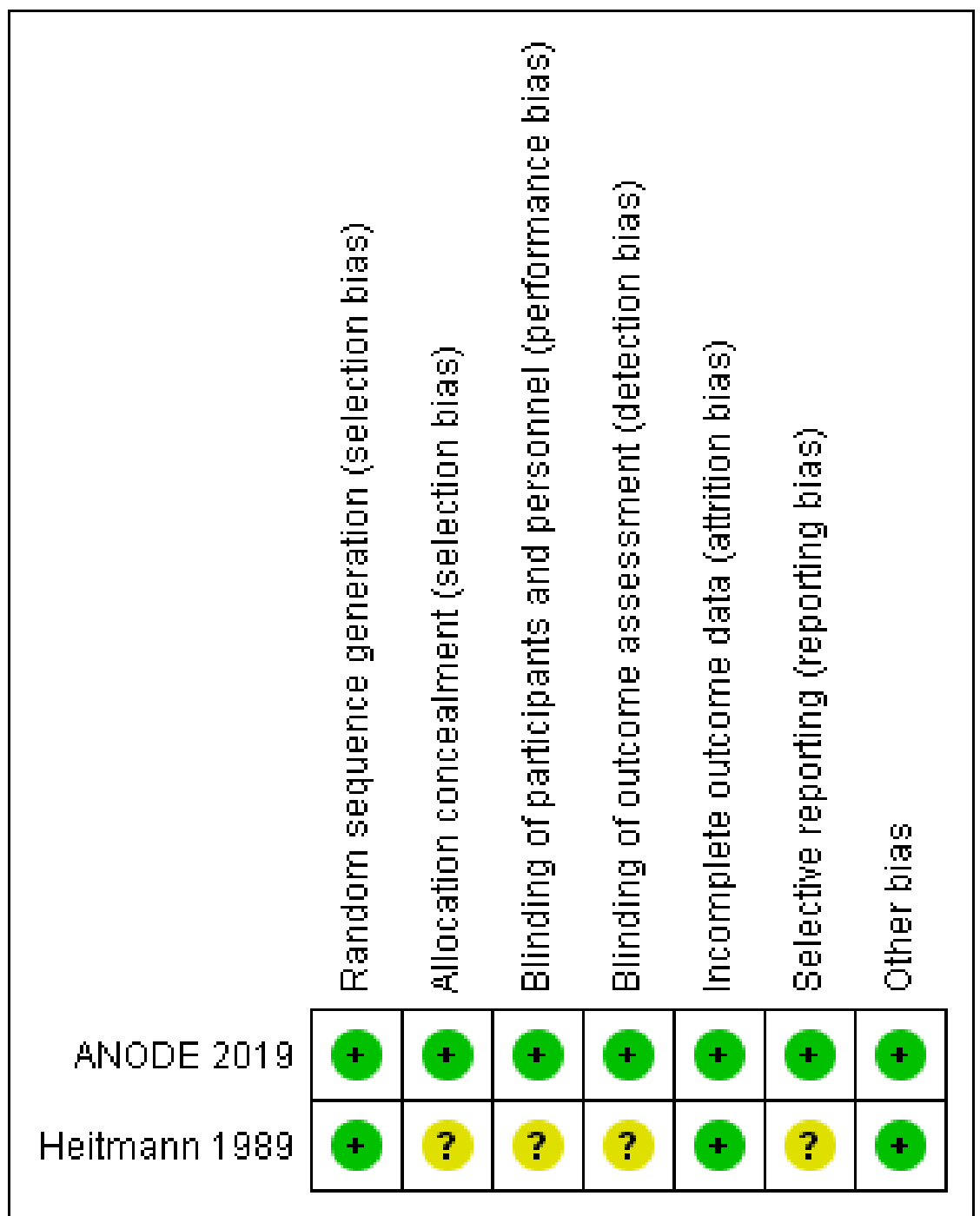

\section{Allocation}

Heitmann 1989 used a randomisation table to generate allocation sequence, but did not report concealment of randomisation. There were more vacuum deliveries than forceps deliveries but they were equally balanced between the two groups (vacuum rate was $57 \%$ in the cefotetan group and $59 \%$ in the no treatment group).

ANODE 2019 used permuted blocks of variable size for random sequence generation and the randomisation list was concealed by a designated independent trial programmer and sealed, sequentially numbered, indistinguishable packs containing the prepared drug or placebo.

\section{Blinding}

There were no details of the blinding of intervention to either women or clinicians as well as the outcome measurements in one study (Heitmann 1989). It could be assumed that it was not blinded because the comparison was no treatment. However, the main outcome was objectively measured so it was unlikely to have been influenced by lack of blinding (Heitmann 1989).
We assessed that the method of ANODE 2019 study for blinding of participant, caregiver and outcome assessors was of low risk of bias.

\section{Incomplete outcome data}

The number of samples given at intervention was the same as those at outcome measure; however, the intention-to-treat analysis was not clearly described in Heitmann 1989 For ANODE 2019, the number of primary outcomes were complete but secondary outcomes showed $24 \%$ loss to follow-up; however, it was balanced between both groups thus it was assessed as being of low risk of bias.

\section{Selective reporting}

In Heitmann 1989, the study protocol was not available; therefore, there was insufficient information to permit judgement. Also, there was no attempt to analyse the subgroups according to the type of delivery (Heitmann 1989). Outcomes in the study of ANODE 2019 were reported as defined in the protocol. 


\section{Other potential sources of bias}

Both studies appeared to be free of other sources of bias.

\section{Effects of interventions}

See: Summary of findings for the main comparison Any antibiotics compared to placebo or no treatment for operative vaginal delivery

Two studies, involving 3813 women undergoing either vacuum or forceps deliveries, were included. One study involving 393 women was judged as unclear risk of bias in most domains comparing the antibiotic intravenous cefotetan after cord clamping compared with no treatment (Heitmann 1989). The other study involving 3420 women had low risk of bias comparing a single dose of intravenous amoxicillin and clavulanic acid with placebo using 20 $\mathrm{mL}$ of intravenous sterile $0.9 \%$ saline (ANODE 2019).

\section{Primary outcome}

Prophylactic antibiotics reduce infected episiotomy/laceration presenting with superficial perineal wound infection (risk ratio (RR) $0.53,95 \%$ confidence interval $(\mathrm{Cl}) 0.40$ to 0.69 ; women $=3420 ; 1$ study; high-certainty evidence; Analysis 1.1), deep perineal wound infection (RR 0.46, 95\% Cl 0.31 to 0.69; women = 3420; 1 study; highcertainty evidence; Analysis 1.2), and wound breakdown (RR 0.52, $95 \% \mathrm{Cl} 0.43$ to 0.63 ; women $=2593 ; 1$ study; moderate-certainty evidence; Analysis 1.4). We are unclear of the effect on infected episiotomy/laceration presenting with organ or space infection (RR $0.11,95 \% \mathrm{Cl} 0.01$ to 2.05 ; women $=3420 ; 1$ study; low-certainty evidence; Analysis 1.3) or on endometritis (average RR 0.32, 95\% $\mathrm{Cl} 0.04$ to $2.64 ; 15 / 1907$ versus $30 / 1906$; women $=3813$; 2 studies; random-effects model; $1^{2}=58 \%$; low-certainty evidence; Analysis 1.5) because the certainty of the evidence was low and the $\mathrm{Cls}$ were wide and included no effect. We could not perform subgroup or sensitivity analyses of endometritis because only two studies were included. Prophylactic antibiotics also probably lower serious infectious complications (RR $0.44,95 \% \mathrm{Cl} 0.22$ to 0.89 ; women = 3420; 1 study; high-certainty evidence; Analysis 1.6). Prophylactic antibiotics have an important effect on reduction of confirmed or suspected maternal infection (Analysis 1.7). The two included studies did not report fever or urinary tract infection.

Six primary outcomes were assessed as being of low- to highcertainty evidence according to GRADE. High-certainty evidence on superficial or deep perineal wound infection and serious infectious complications were shown.

\section{Secondary outcomes}

It is unclear whether antibiotics have any impact on maternal adverse reactions $(\mathrm{RR} 2.00,95 \% \mathrm{Cl} 0.18$ to 22.05 ; women = 2593; 1 study; low-certainty evidence; Analysis 1.8) and maternal length of stay (MD 0.09 days, $95 \% \mathrm{Cl}-0.23$ to 0.41 ; women = 393; 1 study; low-certainty evidence; Analysis 1.9), because the results for both of these were based on low-certainty evidence with confidence intervals that included both benefit and harm. Secondary outcomes, not prespecified in the protocol, were perineal pain (Analysis 1.10), use of pain relief for perineal pain (Analysis 1.11), need for additional perineal care (Analysis 1.12), dyspareunia (Analysis 1.13), breastfeeding at six weeks (Analysis 1.14), perineum "ever too painful or uncomfortable" to feed baby (Analysis 1.15), any primary care or home visits in relation to perineum (Analysis 1.16), any outpatient visit in relation to perineum (Analysis 1.17), maternal hospital re-admission (Analysis 1.18), maternal health-related quality of life (Analysis 1.19) and costs (Analysis 1.20). Prophylactic antibiotics slightly improve perineal pain and health consequences of perineal pain, probably reduce the costs, and may slightly reduce the maternal hospital re-admission and health-related quality of life. Neonatal adverse reactions were not reported in any included trials.

Two outcomes, maternal adverse reactions and maternal length of stay, were assessed as being of low certainty according to GRADE. The reasons for downgrading the certainty of the evidence were because of very serious imprecision due to wide Cls crossing the line of no effect, a small number of events and serious limitations in study design with many domains being at unclear risk of bias.

\section{DISCUSSION}

\section{Summary of main results}

Two studies, involving 3813 women undergoing either vacuum or forceps deliveries, were included. The studies compared the prophylactic antibiotics with intravenous cefotetan after cord clamping or a single dose of amoxicillin and clavulanic acid after giving birth compared with no treatment or placebo. One study published in 1989 reported only two out of the nine outcomes specified in this review. One recent study published in 2019 reported almost all outcomes specified, except fever, urinary tract infection and neonatal adverse reactions. In addition, perineal pain and its health consequences due to perineal pain, maternal hospital re-admission, and health-related quality of life, which were not prespecified in the protocol, were also reported.

Prophylactic antibiotics reduce infected episiotomy/laceration presenting with superficial or deep perineal wound infection and wound breakdown with high-certainty and moderate-certainty evidence, respectively. We are unclear about the effect of prophylactic antibiotics on endometritis or organ or space perineal wound infection due to low-certainty evidence. Antibiotic prophylaxis probably lowers serious infectious complications with high-certainty evidence and has an important effect on reduction of confirmed or suspected maternal infection. The two included studies did not report on fever or urinary tract infection. It is unclear whether prophylactic antibiotics have any impact on maternal adverse reactions and maternal length of stay with lowcertainty evidence, respectively. Prophylactic antibiotics slightly improve perineal pain and health consequences of perineal pain and probably reduce costs, and may slightly reduce the maternal hospital re-admission and health-related quality of life. Neonatal adverse reactions were not reported in either of the included trials. Prophylactic antibiotics did not have an important effect on dyspareunia or breastfeeding at six weeks. Prophylactic antibiotics may slightly reduce maternal hospital re-admission and healthrelated quality of life.

\section{Overall completeness and applicability of evidence}

There were only two included studies in this review (ANODE 2019; Heitmann 1989). The large multi-centre trial involving 3420 women(ANODE 2019) dominates the analyses, with only two outcomes including data from the older, smaller trial (Heitmann 1989). The sample size of the first trial ( $n=393$ women) (Heitmann 
1989) was one tenth that of the large, multi-centre trial (ANODE 2019).

In a recent survey, although the evidence has been lacking to support the use of antibiotic prophylaxis in operative vaginal delivery, it was reported to be widely used in clinical practice (Liabsuetrakul 2014a). From our review, there were important effects of prophylactic antibiotics on reduction of infected episiotomy/laceration presenting with superficial or deep perineal wound infection and wound breakdown. Prophylactic antibiotics probably lower serious infectious complications. However, our review findings have been mainly due to the findings from a large, multi-centre trial conducted in the UK using a single dose of amoxicillin and clavulanic acid after giving birth. The practice of operative vaginal deliveries and rate of postpartum infections are different across settings (ACOG 2015). A literature review of 10 studies conducted in the USA and the UK on postpartum infection in women undergoing operative vaginal delivery showed the incidence of infectious morbidities varying from $0.7 \%$ to $16 \%$, which was higher in forceps delivery than vacuum extraction (Mohamed-Ahmed 2019). More trials in different settings where the practice is more widespread are needed particularly in low- and middle-income settings.

In addition, there was insufficient information on the scale used to assess the perineal pain in the ANODE 2019 trial. The pain results were presented as a binary outcome (ANODE 2019), which could be a limitation. In the trial protocol (Knight 2018), the pain tools referred to were described in two studies (Dudley 2017; McCandlish 1998), which defined pain as none, mild, moderate and severe. It is therefore unclear how the binary pain outcomes were calculated.

\section{Quality of the evidence}

Overall, the included studies were at low risk of bias. The certainty of the evidence using GRADE was low- to high-certainty evidence. The reasons for downgrading the certainty of the evidence were due to limitations in study design, imprecision and inconsistency. High-certainty evidence was found for prophylactic antibiotics on reducing infected episiotomy/laceration (superficial and deep perineal wound infection and serious infectious complications in operative vaginal deliveries). The certainty of evidence on infected episiotomy/laceration presenting with wound breakdown was downgraded due to high loss to follow-up at six weeks postpartum. We downgraded two levels for very serious imprecision due to wide confidence intervals crossing the line of no effect and small number of events for infected episiotomy/laceration presenting with organ or space perineal wound infection and maternal adverse reactions. The certainty of evidence on endometritis was downgraded due to inconsistency and imprecision. We downgraded the certainty of evidence on maternal length of stay due to a small trial with unclear risk of bias (Heitmann 1989).

\section{Potential biases in the review process}

We conducted extensive search strategies with no language restriction and all potential studies were checked by two review authors to prevent the reporting biases. Independently blinding processes of study selection, assessing risk of biases, and data extraction using clearly-defined criteria and checklists were performed to minimise potential biases.

\section{Agreements and disagreements with other studies or reviews}

There are no other systematic reviews on antibiotic prophylaxis for operative vaginal delivery published. One additional randomised controlled trial on this issue has been conducted and was published in 2019 (ANODE 2019) and this is now included in this review.

\section{AUTHORS' CONCLUSIONS}

\section{Implications for practice}

Evidence from two studies conducted in high-income countries, one small and one big trial, suggest that prophylactic antibiotics have an important effect on reduction of superficial and deep perineal wound infection or serious infectious complications in women undergoing operative vaginal deliveries. The effect of antibiotic prophylaxis is unclear on endometritis, organ or space perineal wound infection, maternal adverse reactions and maternal length of stay due to low-certainty evidence. Prophylactic antibiotics slightly improve perineal pain and health consequences of perineal pain and probably reduce costs, and may slightly reduce the maternal hospital re-admission and health-related quality of life.

\section{Implications for research}

Future research on antibiotic prophylaxis for operative vaginal delivery, particularly on type of antibiotics and route or timing of administration, is needed to clarify whether this intervention is effective in reducing postpartum morbidity. As the evidence was mainly derived from a single multi-centre study conducted in a high-income setting, trials in different settings, especially in lowand middle-income countries are required. Outcomes on fever, urinary tract infection and neonatal adverse reactions have not been reported in the included studies and should be considered in future trials.

\section{ACKNOWLEDGEMENTS}

We thank Zarko Alfirevic, Eduardo Bergel, Mario Festin, Simon Gates and the Cochrane Pregnancy and Childbirth Group Consumer Panel for their helpful comments on the protocol and the first published version of this review. We also thank Lynn Hampson for the translation (De Meeus 1991) and Erika Ota for preparing the 'Summary of findings' table in the 2014 update.

Erika Ota's work was financially supported by the UNDP/ UNFPA/UNICEF/WHO/World Bank Special Programme of Research, Development and Research Training in Human Reproduction (HRP), Department of Reproductive Health and Research (RHR), World Health Organization. The named authors are responsible for the views expressed in this publication (2014 update).

This project was supported by the National Institute for Health Research (NIHR), via Cochrane Infrastructure funding to Cochrane Pregnancy and Childbirth. The views and opinions expressed therein are those of the authors and do not necessarily reflect those of the Evidence Synthesis Programme, the NIHR, National Health Service (NHS) or the Department of Health and Social Care.

This review is supported by funding from the World Health Organization (WHO) and the UNDP-UNFPA-UNICEF-WHO-World Bank Special Programme of Research, Development and Research 
Training in Human Reproduction (HRP) to Cochrane Pregnancy and Childbirth (University of Liverpool). HRP supports and coordinates research on a global scale, synthesizes research through systematic reviews of literature, builds research capacity in low-income countries and develops dissemination tools to make efficient use of ever-increasing research information. In addition to its cosponsors, the International Planned Parenthood Federation (IPPF) and UNAIDS are both members of HRP's governing body.
As part of the pre-publication editorial process, this review has been commented on by four peers (an editor and three referees who are external to the editorial team) and the Group's Statistical Adviser. The authors are grateful to the following peer reviewers for their time and comments: Mario Philip R. Festin MD, University of the Philippines Manila, College of Medicine and Philippine General Hospital; Dr Kevin P Hanretty MD FRCOG, Obstetrici and Gynaecologist (retired); Alfred Osoti (MBChB, MMed, MPH, $\mathrm{PhD}$ ), University of Nairobi, Kenya, Affiliate Associate Professor, University of Washington, USA. 


\section{R E F E E N CE S}

\section{References to studies included in this review}

ANODE 2019 \{published data only\}

ANODE CG, Knight M. Lb 3: prophylactic antibiotics for the prevention of infection following operative vaginal delivery: the ANODE trial. American Journal of Obstetrics and Gynecology 2019;220(1):S685.

ISRCTN11166984. ANODE: Prophylactic antibiotics for the prevention of infection following operative delivery. isrctn.com/ ISRCTN11166984 (date received 23 September 2015).

* Knight M, Chiocchia V, Partlett C, Rivero-Arias O, Hua X, Hinshaw K, et al. Prophylactic antibiotics in the prevention of infection after operative vaginal delivery (ANODE): a multicentre randomised controlled trial. Lancet 2019;393(10189):2395-403.

Knight M, Mottram L, Gray S, Partlett C, Juszczak E. Prophylactic antibiotics for the prevention of infection following operative vaginal delivery (ANODE): study protocol for a randomised controlled trial. Trials 2018;19(1):395.

Heitmann 1989 \{published data only\}

Heitmann JA, Benrubi GI. Efficacy of prophylactic antibiotics for the prevention of endomyometritis after forceps delivery. Southern Medical Journal 1989;82:960-2.

\section{References to studies excluded from this review}

De Meeus 1991 \{published data only\}

* De Meeus JB, Kibler MP, Desayes M, Toullat G, Magnin G. Antibiotic prophylaxis and at risk vaginal deliveries: randomised study of 200 deliveries [Antibioprophylaxie et accouchements a risque par voie basse: etude randomisee de 200 accouchements]. Journal de Gynecologie, Obstetrique et Biologie de la Reproduction 1991;20:599.

De Meeus JB, Klibler MP, Deshayes M, Toullat G, Magnin G. Randomized study of 200 vaginal deliveries at risk of infection: relevance of antibiotic prophylaxis [Etude randomisee de 200 accouchements par voie basse a risque infectieux: interet de I'antibioprophylaxie]. Journal de Gynecologie, Obstetrique et Biologie de la Reproduction 1991;20:454.

\section{Additional references}

\section{ACOG 2015}

American College of Obstetricians and Gynecologists. ACOG Practice Bulletin No. 154: Operative vaginal delivery. Obstetrics and Gynecology 2015;126(5):e56-e65.

\section{ACOG 2018}

American College of Obstetricians and Gynecologists. ACOG Practice Bulletin No. 199: Use of prophylactic antibiotics in labor and delivery. Obstetrics and Gynecology 2018;132(3):e103e119. [PUBMED 30134425]

\section{Acosta 2014}

Acosta CD, Kurinczuk JJ, Lucas DN, Tuffnell DJ, Sellers S, Knight M, for the United Kingdom Obstetric Surveillance System. Severe maternal sepsis in the UK, 2011-2012: a national case-control study. PLOS Medicine 2014;11(7):e1001672.

\section{Angioli 2000}

Angioli R, Gomes-Marin O, Cantuaria G, O'Sullivan MJ. Severe perineal lacerations during vaginal delivery: the University of Miami experience. American Journal of Obstetrics and Gynecology 2000;182:1083-5.

\section{Boucoiran 2010}

Boucoiran I, Valerio L, Bafghi A, Delotte J, Bongain A. Spatulaassisted deliveries: a large cohort of 1065 cases. European Journal of Obstetrics, Gynecology, and Reproductive Biology 2010;151(1):46-51.

\section{Buppasiri 2014}

Buppasiri P, Lumbiganon P, Thinkhamrop J, Thinkhamrop B. Antibiotic prophylaxis for third- and fourth-degree perineal tear during vaginal birth. Cochrane Database of Systematic Reviews 2014, Issue 10. [DOI: 10.1002/14651858.CD005125.pub4]

\section{Cammu 2011}

Cammu H, Martens G, Keirse MJ. Mothers' level of education and childbirth interventions: a population-based study in Flanders, Northern Belgium. Birth 2011;38(3):191-9.

\section{Chaim 2000}

Chaim W, Bashiri A, Bar-David J, Shoham-Vardi I, Mazor M. Prevalence and clinical significance of postpartum endometritis and wound infection. Infectious Diseases in Obstetrics and Gynecology 2000;8:77-82.

\section{Chang 1992}

Chang PL, Newton ER. Predictors of antibiotic prophylactic failure in post-cesarean endometritis. Obstetrics \& Gynecology 1992;80(1):117-22.

\section{Criscuolo 1990}

Criscuolo JL, Kibler MP, Micholet S, Magnin G, Ducroz B, Toullat $\mathrm{G}$, et al. The value of antibiotic prophylaxis during intrauterine procedures during vaginal delivery. A comparative study of 500 patients. Journal de Gynecologie, Obstetrique et Biologie de la Reproduction 1990;19:909-18.

\section{Dancer 2004}

Dancer SJ. How antibiotics can make us sick: the less obvious adverse effects of antimicrobial chemotherapy. Lancet Infectious Diseases 2004;6:611-9.

\section{Dare 1998}

Dare FO, Bako AU, Ezechi OC. Puerperal sepsis: a preventable post-partum complication. Tropical Doctor 1998;28:92-5. 


\section{Dudley 2017}

Dudley L, Kettle C, Thomas PW, Ismail KM. Perineal resuturing versus expectant management following vaginal delivery complicated by a dehisced wound (PREVIEW): a pilot and feasibility randomised controlled trial. BMJ Open 2017;7(2):e012766.

\section{Duggal 2008}

Duggal N, Mercado C, Daniels K, Bujor A, Caughey AB, ElSayed YY. Antibiotic prophylaxis for prevention of postpartum perineal wound complications: a randomized controlled trial. Obstetrics and Gynecology 2008;111(6):1268-73.

\section{Eschenbach 1986}

Eschenbach DA, Rosene K, Tompkins LS, Watkins H, Gravett MG. Endometrial cultures obtained by a triple-lumen method from afebrile and febrile postpartum women. Journal of Infectious Diseases 1986;153:1038-45.

\section{Fernandez 1993}

Fernandez H, Gagnepain A, Bourget P, Peray P, Frydman R, Papiernik E, et al. Antibiotic prophylaxis against postpartum endometritis after vaginal delivery: a prospective randomized comparison between Amox-CA (Augmentin) and abstention. European Journal of Obstetrics \& Gynecology and Reproductive Biology 1993;50:169-75.

\section{Goldberg 2003}

Goldberg J, Hyslop T, Tolosa JE, Sultana C. Racial differences in severe perineal lacerations after vaginal delivery. American Journal of Obstetrics and Gynecology 2003;188(4):1063-7.

\section{Hagadorn-Freathy 1991}

Hagadorn-Freathy AS, Yeomen ER, Hankins GV. Validation of the 1988 ACOG forceps classification system. Obstetrics \& Gynecology 1991;77:356-60.

\section{Hanley 2010}

Hanley GE, Janssen PA, Greyson D. Regional variation in the cesarean delivery and assisted vaginal delivery rates. Obstetrics and Gynecology 2010;115(6):1201-8.

\section{Hehir 2013}

Hehir MP, Reidy FR, Wilkinson MN, Mahony R. Increasing rates of operative vaginal delivery across two decades: accompanying outcomes and instrument preferences. European Journal of Obstetrics, Gynecology, and Reproductive Biology 2013;171(1):40-3.

\section{Higgins 2011}

Higgins JP, Green S, editors. Cochrane Handbook for Systematic Reviews of Interventions Version 5.1.0 [updated March 2011]. The Cochrane Collaboration, 2011. Available from www.cochrane-handbook.org.

\section{Janisch 1979}

Janisch H, Philipp K, Riss P. The effect of antibiotic prophylaxis in vaginal obstetric procedures. Wiener Klinische Wochenschrift 1979;91:227-30.

\section{Janni 2002}

Janni W, Schiessl B, Peschers U, Huber S, Strobl B, Hantschmann $P$, et al. The prognostic impact of a prolonged second stage of labor on maternal and fetal outcome. Scandinavian Association of Obstetricians and Gynaecologists 2002;81(3):214-21.

\section{Johnson 2004}

Johnson JH, Figueroa R, Garry D, Elimian A, Maulik D. Immediate maternal and neonatal effects of forceps and vacuum-assisted deliveries. Obstetrics and Gynecology 2004;103(3):513-8.

\section{Kabiru 2001}

Kabiru WN, Jamieson D, Graves W, Lindsay M. Trends in operative vaginal delivery rates and associated maternal complication rates in an inner-city hospital. American Journal of Obstetrics and Gynecology 2001;184:1112-4.

\section{Knight 2018}

Knight M, Mottram L, Gray S, Partlett C, Juszczak E, and the ANODE collaborative group. Prophylactic antibiotics for the prevention of infection following operative vaginal delivery (ANODE): study protocol for a randomised controlled trial. Trials 2018;19(1):395.

\section{Kok 2000}

Kok $\mathrm{M}$, Pechère J. Nature and pathogenicity of microorganisms. In: Armstrong D, Cohen J editor(s). Infectious Diseases. London: Mosby, 2000:1-26.

\section{Lawani 2014}

Lawani LO, Anozie OB, Ezeonu PO, lyoke CA. Comparison of outcomes between operative vaginal deliveries and spontaneous vaginal deliveries in southeast Nigeria. International Journal of Gynecology \& Obstetrics 2014;125(3):206-9.

\section{Liabsuetrakul 2014a}

Liabsuetrakul T, Lumbiganon P, Mori R, Gülmezoglu M, Souza JP, for the WHO Global Survey on Maternal and Perinatal Health. A secondary analysis of the WHO Global Survey on Maternal and Perinatal Health for antibiotics used in vaginal deliveries. International Journal of Gynecology \& Obstetrics 2014;124(3):240-3.

\section{Liu 2005}

Liu S, Heaman M, Joseph KS, Liston RM, Huang L, Sauve R, et al. Maternal Health Study Group of the Canadian Perinatal Surveillance System. Risk of maternal postpartum readmission associated with mode of delivery. Obstetrics and Gynecology 2005;105(4):836-42.

\section{Lumbiganon 2010}

Lumbiganon P, Laopaiboon M, Gülmezoglu M, Souza JP, Taneepanichkul S, Ruyan P, et al. Method of delivery and pregnancy outcomes in Asia: the WHO global survey on maternal and perinatal health 2007-08. Lancet 2010;375:490-9. 


\section{McCandlish 1998}

McCandlish R, Bowler U, van Asten H, Berridge G, Winter C, Sames $L$, et al. A randomised controlled trial of care of the perineum during second stage of normal labour. British Journal of Obstetrics and Gynaecology 1998;105(12):1262-72.

\section{Mohamed-Ahmed 2019}

Mohamed-Ahmed O, Hinshaw K, Knight M. Operative vaginal delivery and post-partum infection. Best Practice \& Research Clinical Obstetrics and Gynaecology 2019;56:93-106.

\section{Mola 2011}

Mola GD, Kuk J. Operative vaginal delivery at Port Moresby General Hospital from 1977 to 2010. Papua and New Guinea Medical Journal 2011;54(3-4):174-84.

\section{Ngoc 2005}

Ngoc NT, Sloan NL, Thach TS, Liem LK, Winikoff B. Incidence of postpartum infection after vaginal delivery in Viet Nam. Journal of Health, Population and Nutrition 2005;23:121-30.

\section{Nkwabong 2011}

Nkwabong E, Nana PN, Mbu R, Takang W, Ekono MR, Kouam L. Indications and maternofetal outcome of instrumental deliveries at the university teaching hospital of Yaoundé, Cameroon. Tropical Doctor 2011;41:5-7.

\section{Panigrahy 2008}

Panigrahy R, Welsh J, Mackenzie F, Owen P, for the Perinatal Effectiveness Committee in Glasgow (PEC). A complete audit cycle of management of third/fourth degree perineal tears. Journal of Obstetrics and Gynaecology 2008;28:305-9.

\section{Pranchev 1993}

Pranchev N, Istatkov M, Mekhandzhieva V. The current clinical approach in puerperal endometritis. Akusherstvo i Ginekologiia (Sofiia) 1993;32:12-4.

\section{Prapas 2009}

Prapas N, Kalogiannidis I, Masoura S, Diamanti E, Makedos A, Drossou $\mathrm{D}$, et al. Operative vaginal delivery in singleton term pregnancies: short-term maternal and neonatal outcomes. Hippokratia 2009;13(1):41-5.

\section{RCOG 2011}

Royal College of Obstetricians and Gynaecologists. Green-top Guideline No. 26: Operative vaginal delivery. RCOG: London. London: RCOG, 2011.

\section{Rechlin 1988}

Rechlin VD, Wolf M, Koeniger W. Value of the preventive use of antibiotics following vaginal obstetric operations. Zentralblatt fur Gynakologie 1988;110:570-4.

\section{RevMan 2014 [Computer program]}

The Nordic Cochrane Centre, The Cochrane Collaboration. Review Manager (RevMan). Version 5.3. Copenhagen: The Nordic Cochrane Centre, The Cochrane Collaboration, 2014.

\section{Smail 2014}

Smaill FM, Grivell RM. Antibiotic prophylaxis versus no prophylaxis for preventing infection after cesarean section. Cochrane Database of Systematic Reviews 2014, Issue 10. [DOI: 10.1002/14651858.CD007482.pub3]

\section{Stray-Pedersen 1988}

Stray-Pedersen B, Solberg VM, Torkildsen E, Lie S, Velken M, Aaserud J, et al. Postpartum bacteriuria: a multicenter evaluation of different screening procedures and a controlled short-course treatment trial with amoxycillin. European Journal of Obstetrics \& Gynecology and Reproductive Biology 1988;31:163-71.

\section{Towers 1998}

Towers CV, Carr MH, Padilla G, Asrat T. Potential consequences of widespread antepartal use of ampicillin. American Journal of Obstetrics and Gynecology 1998;179:879-83.

\section{Walsh 2013}

Walsh CA, Robson M, McAuliffe FM. Mode of delivery at term and adverse neonatal outcomes. Obstetrics and Gynecology 2013;121(1):122-8.

\section{Weinstein 1996}

Weinstein JW, Roe M, Towns M, Sanders L, Thorpe JJ, Corey R, et al. Resistant enterococci: a prospective study of prevalence, incidence, and factors associated with colonization in a university hospital. Infection Control and Hospital Epidemiology 1996;17:36-41.

\section{Williams 1991}

Williams MC, Knuppel RA, Wiss A, Kanarak KS. A randomized comparison of assisted vaginal delivery by obstetric forceps and polyethylene vacuum cup. Obstetrics \& Gynecology 1991;78:789-94.

\section{References to other published versions of this review \\ Liabsuetrakul 2003}

Liabsuetrakul T, Choobun T, Peeyananjarassri K, Islam M. Antibiotic prophylaxis for operative vaginal delivery. Cochrane Database of Systematic Reviews 2003, Issue 4. [DOI: 10.1002/14651858.CD004455]

\section{Liabsuetrakul 2004}

Liabsuetrakul T, Choobun T, Peeyananjarassri K, Islam QM. Antibiotic prophylaxis for operative vaginal delivery. Cochrane Database of Systematic Reviews 2004, Issue 3. [DOI: 10.1002/14651858.CD004455.pub2]

\section{Liabsuetrakul 2014b}

Liabsuetrakul T, Choobun T, Peeyananjarassri K, Islam QM. Antibiotic prophylaxis for operative vaginal delivery. Cochrane Database of Systematic Reviews 2014, Issue 10. [DOI: 10.1002/14651858.CD004455.pub3]

\section{Liabsuetrakul 2017}

Liabsuetrakul T, Choobun T, Peeyananjarassri K, Islam QM. Antibiotic prophylaxis for operative vaginal delivery. 
Cochrane Database of Systematic Reviews 2017, Issue 8. [DOI: 10.1002/14651858.CD004455.pub4]

\section{CHARACTERISTICS OF STUDIES}

Characteristics of included studies [ordered by study ID]

\section{ANODE 2019}

Methods A multi-centre, randomised, blinded, controlled trial carried out at 27 hospital obstetric units in the UK.

* Indicates the major publication for the study
Participants
3420 women undergoing all types of operative vaginal birth at 36 weeks or greater gestation.

Women were excluded if they had any clinical indication for antibiotic administration after delivery, third-degree or fourth-degree perineal tears, receipt of antenatal or intrapartum antibiotics with ongoing antibiotics after delivery or a known allergy to penicillin or any of the components of amoxicillin and clavulanic acid, or who had a history of anaphylaxis to another $\beta$-lactam agent.

Setting: 27 hospital obstetric units in the UK; 13 March 2016, and 13 June 2018.
A single dose of intravenous amoxicillin and clavulanic acid ( $1 \mathrm{~g}$ amoxicillin and $200 \mathrm{mg}$ clavulanic acid) as soon as possible and no more than 6 hours after giving birth $(n=1715)$ or placebo group using $20 \mathrm{~mL}$ of intravenous sterile $0.9 \%$ saline within the same timeframe $(n=1705)$.

\section{Outcomes}

Primary outcomes were a confirmed or suspected maternal infection within 6 weeks of delivery as defined as a new antibiotic prescription for a presumed perineal wound-related infection, endometritis or uterine infection, urinary tract infection with systemic features (pyelonephritis or sepsis) or other systemic infection (clinical sepsis); confirmed systemic infection on culture; or endometritis required at least 1 of the following criteria to be met-organisms were cultured from fluid (including amniotic fluid) or tissue from endometrium obtained during an invasive procedure or biopsy, or the woman exhibited at least 2 of fever (> 38 degrees Celsius), abdominal pain, uterine tenderness, or purulent drainage from uterus (with no other recognised cause for the latter 3 symptoms).

Secondary outcomes assessed within 6 weeks of delivery were: systemic sepsis, perineal wound infection, perineal pain, use of pain relief, hospital bed stay until discharge, need for additional perineal care, dyspareunia, ability to sit comfortably to feed the baby, maternal health-related quality of life, breastfeeding, wound breakdown, intervention side effects, healthcare resource use and costs, or adverse events.

Notes Dates study conducted: the trial was carried out between 13 March, 2016 and 13 June 2018.

Funding sources for the study: NIHR Health Technology Assessment programme.

Declarations of interest among primary researchers: 4 authors declared receipt of funding from NIHR outside the submitted work. All other authors have no competing interests to declare.

\section{Risk of bias}

\begin{tabular}{lll}
\hline Bias & Authors' judgement & Support for judgement \\
\hline $\begin{array}{l}\text { Random sequence genera- } \\
\text { tion (selection bias) }\end{array}$ & Low risk & Permuted blocks of variable size was used for random sequence generation. \\
\hline $\begin{array}{l}\text { Allocation concealment } \\
\text { (selection bias) }\end{array}$ & Low risk & $\begin{array}{l}\text { Sealed, sequentially-numbered, indistinguishable packs containing active } \\
\text { drug or placebo as designated randomisation list performed by an indepen- } \\
\text { dent trials programmer. }\end{array}$
\end{tabular}

Blinding of participants Low risk and personnel (perforWomen and most clinicians including research midwives and those taking conmance bias)

All outcomes 
ANODE 2019 (Continued)
Blinding of outcome as-
Low risk
Midwives, nurses, or doctors collecting outcome information were masked to sessment (detection bias) allocation either intervention or placebo.

All outcomes

$\begin{array}{ll}\begin{array}{l}\text { Incomplete outcome data } \\ \text { (attrition bias) }\end{array} & \text { Low risk } \\ \text { All outcomes } & \begin{array}{l}\text { Primary outcome data were complete. Secondary outcome data were incom- } \\ \text { plete with } 24 \% \text { loss to follow-up; however, it was balanced between both } \\ \text { groups. }\end{array}\end{array}$

Outcomes were reported as in the study protocol.

Selective reporting (re- Low risk porting bias)

\begin{tabular}{ll}
\hline Other bias $\quad$ Low risk $\quad$ Study appeared to be free of other sources of bias. \\
\hline
\end{tabular}

Heitmann 1989

\begin{tabular}{ll}
\hline Methods & $\begin{array}{l}\text { Selected by randomisation table to receive treatment or no treatment; not blinded or placebo-con- } \\
\text { trolled. }\end{array}$ \\
\hline Participants & 393 women undergoing instrumental deliveries (either vacuum or forceps deliveries). \\
& $\begin{array}{l}\text { Women were excluded if they had evidence of chorioamnionitis, or other infections, or if they were al- } \\
\text { lergic to penicillin or cephalosporins. }\end{array}$ \\
& Setting: University Hospital of Jacksonville, USA; September 1986 to February 1988. \\
\hline Interventions & $2 \mathrm{~g}$ of cefotetan intravenously after cord clamping ( $\mathrm{n}=192)$ or no treatment ( $\mathrm{n}=201$ ). \\
\hline Outcomes & $\begin{array}{l}\text { Endomyometritis (at least } 1 \text { rise in oral temperature greater than } 38.1 \text { degrees Celsius after the first } 24 \\
\text { hours of delivery and uterine tenderness or foul-smelling lochia with no clinical or laboratory evidence } \\
\text { confirming another source of the fever). }\end{array}$
\end{tabular}

Dates study conducted: the trial was carried out between September 1986 and February 1989.
Funding sources for the study: the funding sources of an included study could not be identified.
Declarations of interest among primary researchers: not reported.

\section{Risk of bias}

\begin{tabular}{lll}
\hline Bias & Authors' judgement & Support for judgement \\
\hline $\begin{array}{l}\text { Random sequence genera- } \\
\text { tion (selection bias) }\end{array}$ & Low risk & A randomisation table was used for random sequence generation. \\
\hline $\begin{array}{l}\text { Allocation concealment } \\
\text { (selection bias) }\end{array}$ & Unclear risk & Allocation concealment could not be interpreted. \\
\hline $\begin{array}{l}\text { Blinding of participants } \\
\text { and personnel (perfor- } \\
\text { mance bias) } \\
\text { All outcomes }\end{array}$ & Unclear risk & Information not clearly mentioned. \\
\hline
\end{tabular}

$\begin{array}{ll}\text { Blinding of outcome as- } & \text { Unclear risk } \quad \text { Who measured the outcome was not mentioned. } \\ \text { sessment (detection bias) } & \end{array}$

All outcomes 
Heitmann 1989 (Continued)

Incomplete outcome data Low risk Same number of samples at intervention given and outcome measure.

(attrition bias)

All outcomes

\begin{tabular}{|c|c|c|}
\hline $\begin{array}{l}\text { Selective reporting (re- } \\
\text { porting bias) }\end{array}$ & Unclear risk & $\begin{array}{l}\text { The study protocol was not available, so there was insufficient information to } \\
\text { permit judgement. }\end{array}$ \\
\hline
\end{tabular}

Other bias Low risk Study appeared to be free of other sources of bias.

Characteristics of excluded studies [ordered by study ID]

\begin{tabular}{|c|c|}
\hline Study & Reason for exclusion \\
\hline De Meeus 1991 & $\begin{array}{l}\text { Abstract only (translated). This randomised study included } 200 \text { women including, not only instru- } \\
\text { mental delivery but also women undergoing manual removal of placenta or uterine exploration, } \\
\text { or both, premature rupture of the membranes of more than } 6 \text { hours and a labour of more than } 8 \\
\text { hours. No details of the interventions were given for either the treatment or the control groups. The } \\
\text { study outcomes of postpartum fever in both comparison groups were given but they were not de- } \\
\text { scribed for subgroups; therefore, there were no data suitable for extraction. We could not find a } \\
\text { published article. We have tried to contact the author but without success to date. }\end{array}$ \\
\hline
\end{tabular}

DATA AND ANALYSES

Comparison 1. Any antibiotics versus placebo or no treatment

\begin{tabular}{|c|c|c|c|c|}
\hline Outcome or subgroup title & $\begin{array}{l}\text { No. of } \\
\text { studies }\end{array}$ & $\begin{array}{l}\text { No. of } \\
\text { partici- } \\
\text { pants }\end{array}$ & Statistical method & Effect size \\
\hline $\begin{array}{l}1 \text { Infected episiotomy/laceration } \\
\text { (superficial perineal wound infec- } \\
\text { tion) }\end{array}$ & 1 & 3420 & Risk Ratio (M-H, Fixed, 95\% Cl) & $0.53[0.40,0.69]$ \\
\hline $\begin{array}{l}2 \text { Infected episiotomy/laceration } \\
\text { (deep perineal wound infection) }\end{array}$ & 1 & 3420 & Risk Ratio (M-H, Fixed, 95\% Cl) & $0.46[0.31,0.69]$ \\
\hline $\begin{array}{l}3 \text { Infected episiotomy/laceration } \\
\text { (organ or space infection) }\end{array}$ & 1 & 3420 & Risk Ratio (M-H, Fixed, 95\% Cl) & $0.11[0.01,2.05]$ \\
\hline $\begin{array}{l}4 \text { Infected episiotomy/laceration } \\
\text { (wound breakdown) }\end{array}$ & 1 & 2593 & Risk Ratio (M-H, Fixed, 95\% Cl) & $0.52[0.43,0.63]$ \\
\hline 5 Endometritis & 2 & 3813 & Risk Ratio (M-H, Random, 95\% Cl) & $0.32[0.04,2.64]$ \\
\hline $\begin{array}{l}6 \text { Serious infectious complica- } \\
\text { tions }\end{array}$ & 1 & 3420 & Risk Ratio (M-H, Fixed, 95\% Cl) & $0.44[0.22,0.89]$ \\
\hline $\begin{array}{l}7 \text { Confirmed or suspected mater- } \\
\text { nal infection }\end{array}$ & 1 & 3420 & Risk Ratio (M-H, Fixed, 95\% Cl) & $0.58[0.49,0.69]$ \\
\hline
\end{tabular}




\begin{tabular}{|c|c|c|c|c|}
\hline Outcome or subgroup title & $\begin{array}{l}\text { No. of } \\
\text { studies }\end{array}$ & $\begin{array}{l}\text { No. of } \\
\text { partici- } \\
\text { pants }\end{array}$ & Statistical method & Effect size \\
\hline 8 Maternal adverse reactions & 1 & 2593 & Risk Ratio (M-H, Fixed, 95\% Cl) & $2.00[0.18,22.05]$ \\
\hline 9 Maternal length of stay & 1 & 393 & Mean Difference (IV, Fixed, 95\% CI) & $0.09[-0.23,0.41]$ \\
\hline 10 Perineal pain & 1 & 2593 & Risk Ratio (M-H, Fixed, 95\% Cl) & $0.84[0.78,0.91]$ \\
\hline $\begin{array}{l}11 \text { Use of pain relief for perineal } \\
\text { pain }\end{array}$ & 1 & 2593 & Risk Ratio (M-H, Fixed, 95\% Cl) & $0.72[0.56,0.92]$ \\
\hline $\begin{array}{l}12 \text { Need for additional perineal } \\
\text { care }\end{array}$ & 1 & 2593 & Risk Ratio (M-H, Fixed, 95\% Cl) & $0.72[0.65,0.80]$ \\
\hline 13 Dyspareunia & 1 & 2593 & Risk Ratio (M-H, Fixed, 95\% Cl) & $1.07[0.93,1.23]$ \\
\hline 14 Breastfeeding at 6 weeks & 1 & 2593 & Risk Ratio (M-H, Fixed, 95\% Cl) & $1.01[0.93,1.09]$ \\
\hline $\begin{array}{l}15 \text { Perineum "ever too painful or } \\
\text { uncomfortable" to feed baby }\end{array}$ & 1 & 2593 & Risk Ratio (M-H, Fixed, 95\% Cl) & $0.69[0.56,0.84]$ \\
\hline $\begin{array}{l}16 \text { Any primary care or home vis- } \\
\text { its in relation to perineum }\end{array}$ & 1 & 2593 & Risk Ratio (M-H, Fixed, 95\% Cl) & $0.73[0.65,0.81]$ \\
\hline $\begin{array}{l}17 \text { Any outpatient visits in rela- } \\
\text { tion to perineum }\end{array}$ & 1 & 2593 & Risk Ratio (M-H, Fixed, 95\% Cl) & $0.55[0.43,0.70]$ \\
\hline $\begin{array}{l}18 \text { Maternal hospital re-admis- } \\
\text { sion }\end{array}$ & 1 & 2593 & Risk Ratio (M-H, Fixed, 95\% Cl) & $0.75[0.55,1.03]$ \\
\hline $\begin{array}{l}19 \text { Maternal health-related quali- } \\
\text { ty of life }\end{array}$ & 1 & 2593 & Mean Difference (IV, Fixed, 95\% CI) & $0.01[-0.00,0.02]$ \\
\hline 20 Costs $(£)$ & 1 & 2593 & Mean Difference (IV, Fixed, 95\% CI) & $-52.60[-97.26,-7.94]$ \\
\hline
\end{tabular}

Analysis 1.1. Comparison 1 Any antibiotics versus placebo or no treatment, Outcome 1 Infected episiotomy/laceration (superficial perineal wound infection).

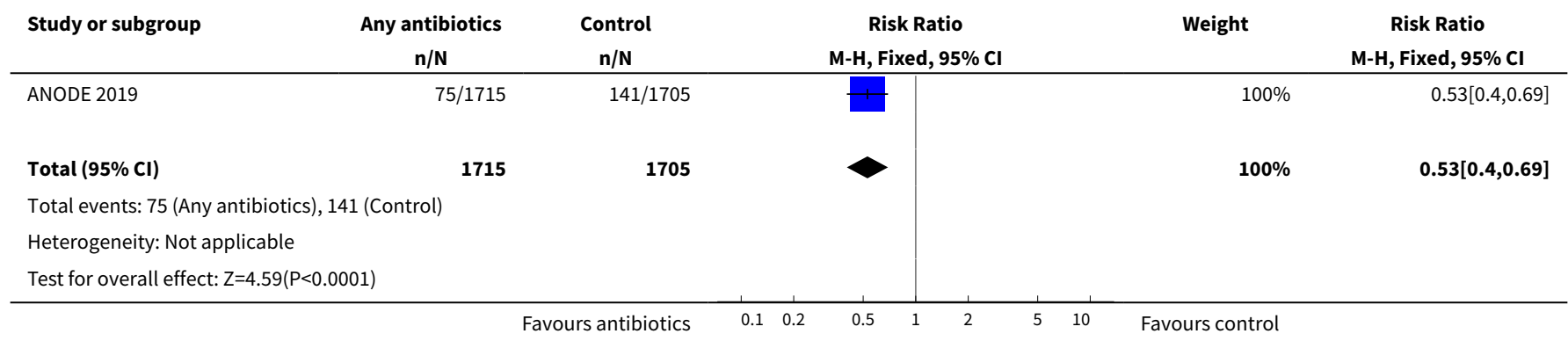


Analysis 1.2. Comparison 1 Any antibiotics versus placebo or no treatment, Outcome 2 Infected episiotomy/laceration (deep perineal wound infection).

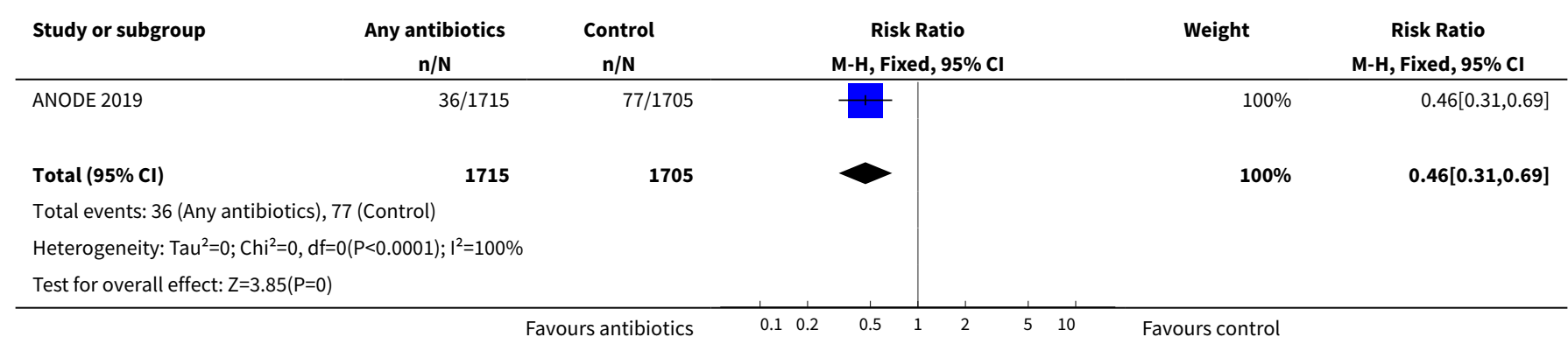

Analysis 1.3. Comparison 1 Any antibiotics versus placebo or no treatment, Outcome 3 Infected episiotomy/laceration (organ or space infection).

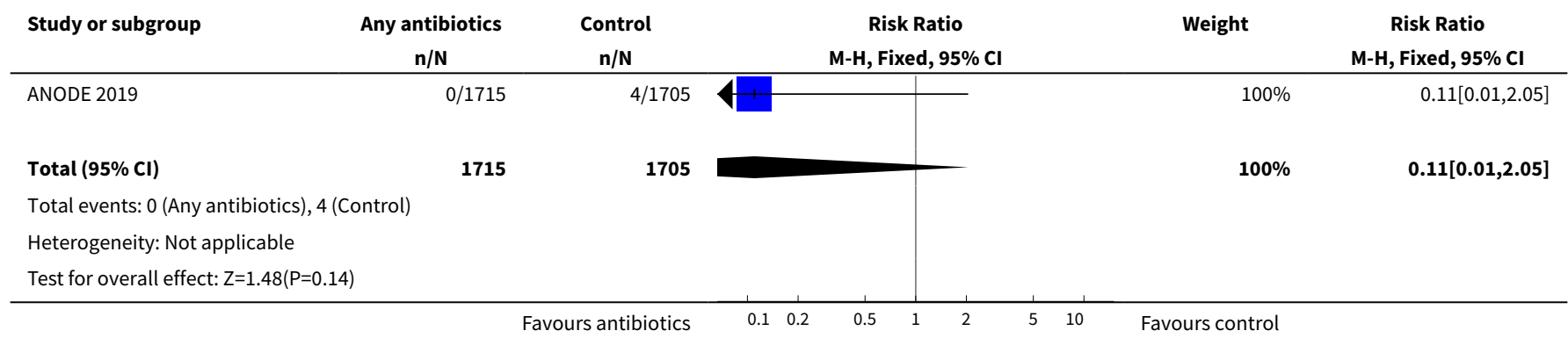

Analysis 1.4. Comparison 1 Any antibiotics versus placebo or no treatment, Outcome 4 Infected episiotomy/laceration (wound breakdown).

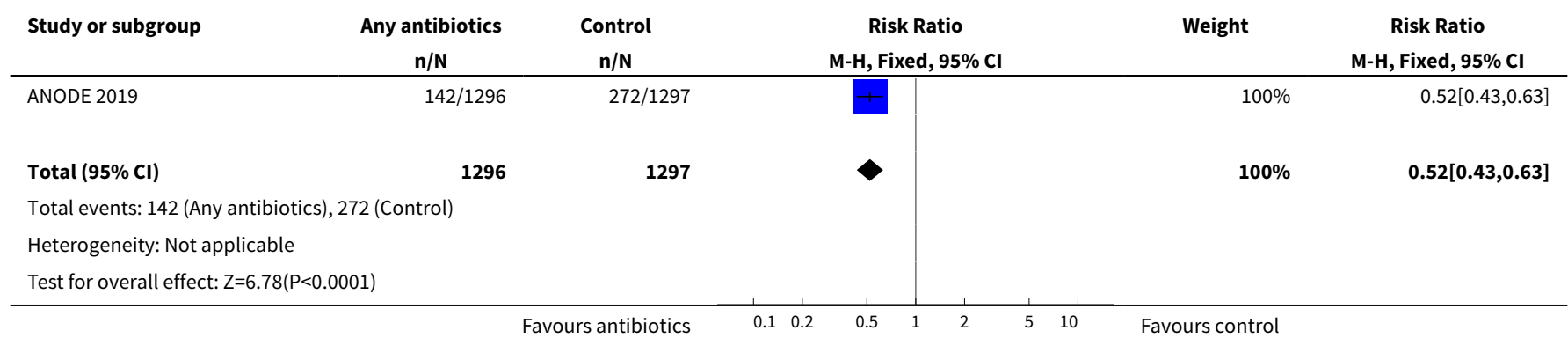

Analysis 1.5. Comparison 1 Any antibiotics versus placebo or no treatment, Outcome 5 Endometritis.

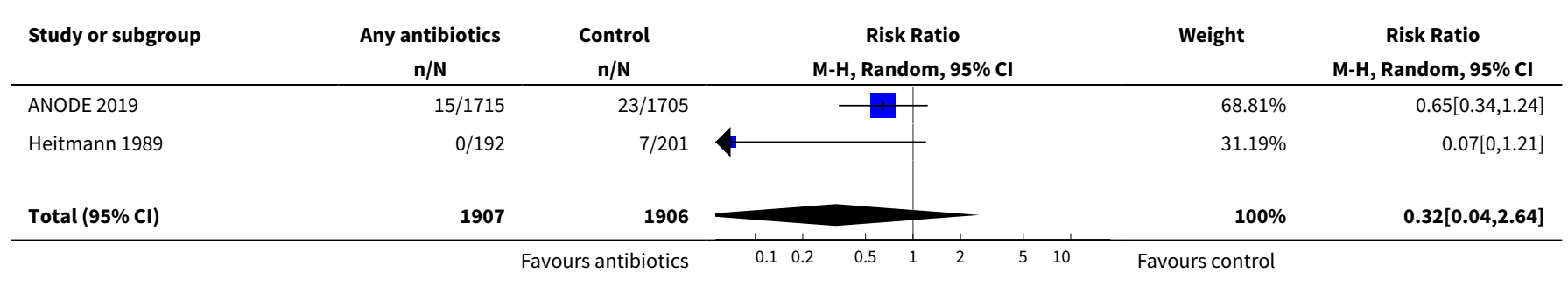




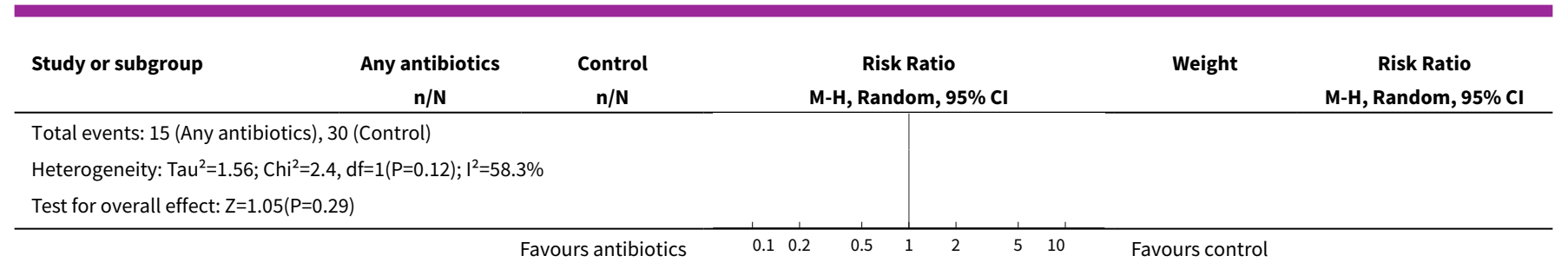

Analysis 1.6. Comparison 1 Any antibiotics versus placebo or no treatment, Outcome 6 Serious infectious complications.

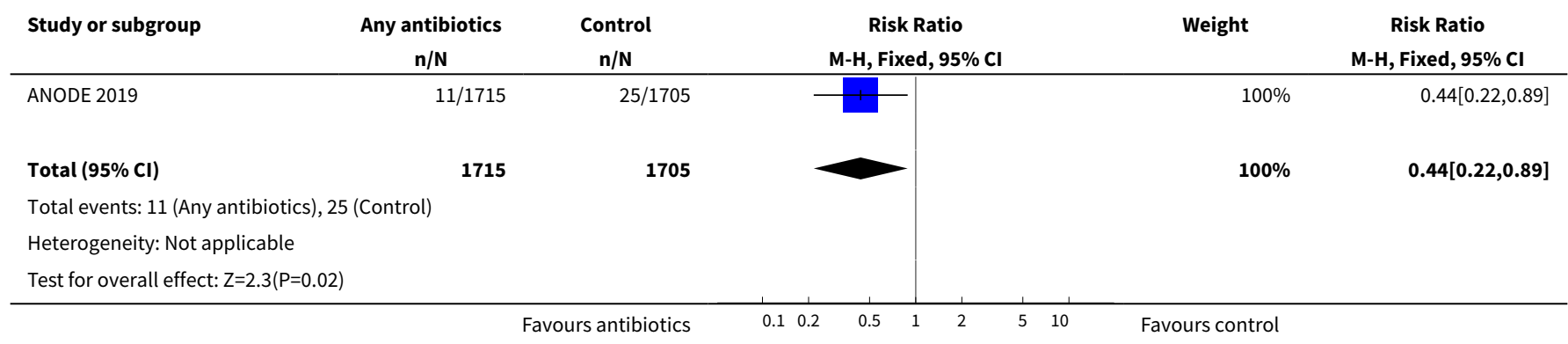

Analysis 1.7. Comparison 1 Any antibiotics versus placebo or no treatment, Outcome 7 Confirmed or suspected maternal infection.

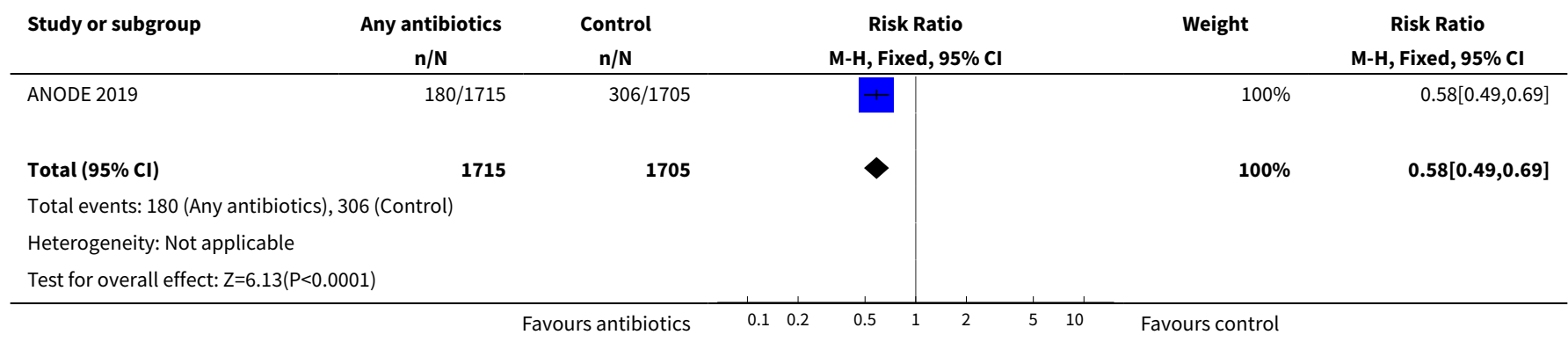

Analysis 1.8. Comparison 1 Any antibiotics versus placebo or no treatment, Outcome 8 Maternal adverse reactions.

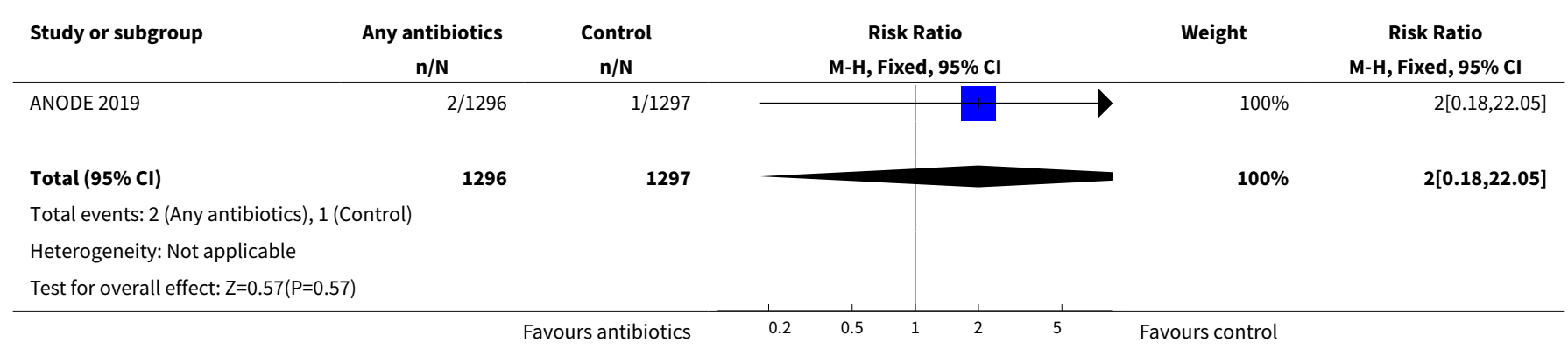


Analysis 1.9. Comparison 1 Any antibiotics versus placebo or no treatment, Outcome 9 Maternal length of stay.

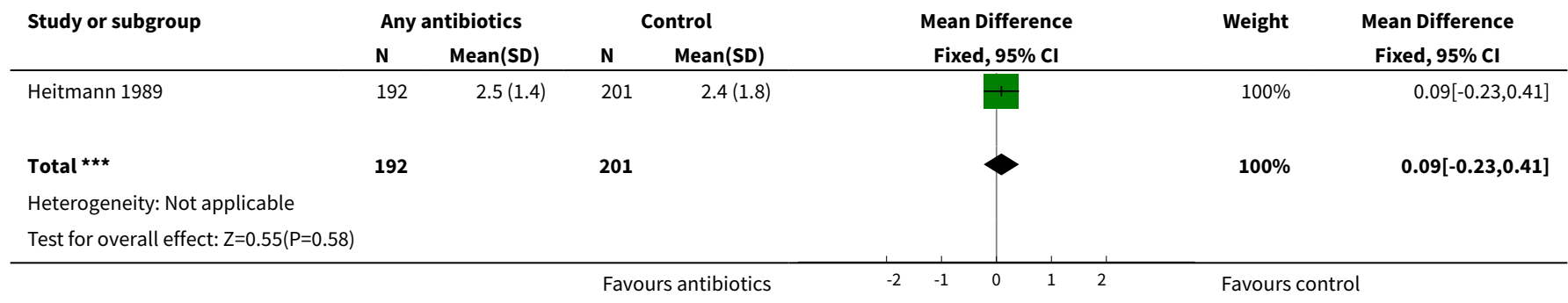

Analysis 1.10. Comparison 1 Any antibiotics versus placebo or no treatment, Outcome 10 Perineal pain.

\begin{tabular}{|c|c|c|c|c|c|}
\hline Study or subgroup & $\begin{array}{c}\text { Any antibiotics } \\
n / N\end{array}$ & $\begin{array}{c}\text { Control } \\
\mathrm{n} / \mathrm{N}\end{array}$ & $\begin{array}{c}\text { Risk Ratio } \\
\text { M-H, Fixed, 95\% Cl }\end{array}$ & Weight & $\begin{array}{c}\text { Risk Ratio } \\
\text { M-H, Fixed, 95\% Cl }\end{array}$ \\
\hline ANODE 2019 & $592 / 1296$ & $707 / 1297$ & & $100 \%$ & $0.84[0.78,0.91]$ \\
\hline Total $(95 \% \mathrm{Cl})$ & 1296 & 1297 & $\boldsymbol{\nabla}$ & $100 \%$ & $0.84[0.78,0.91]$ \\
\hline \multicolumn{6}{|c|}{ Total events: 592 (Any antibiotics), 707 (Control) } \\
\hline \multicolumn{6}{|c|}{ Heterogeneity: Not applicable } \\
\hline Test for overall effect & 01) & & & & \\
\hline
\end{tabular}

Analysis 1.11. Comparison 1 Any antibiotics versus placebo or no treatment, Outcome 11 Use of pain relief for perineal pain.

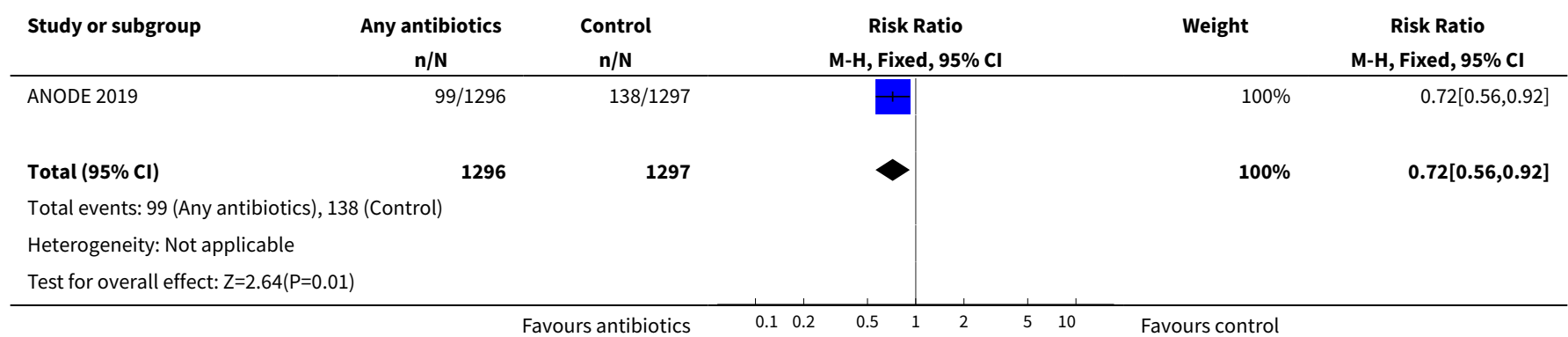

Analysis 1.12. Comparison 1 Any antibiotics versus placebo or no treatment, Outcome 12 Need for additional perineal care.

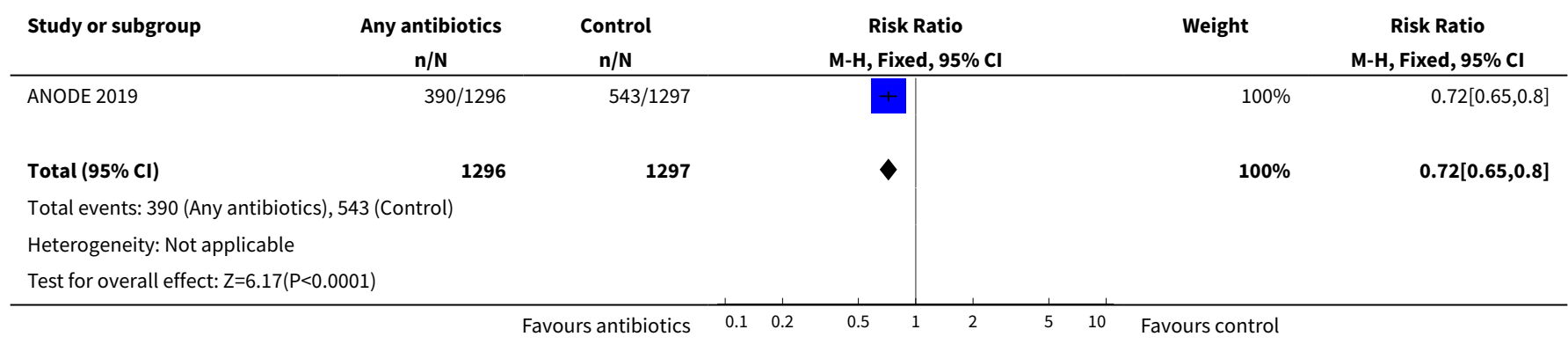


Analysis 1.13. Comparison 1 Any antibiotics versus placebo or no treatment, Outcome 13 Dyspareunia.

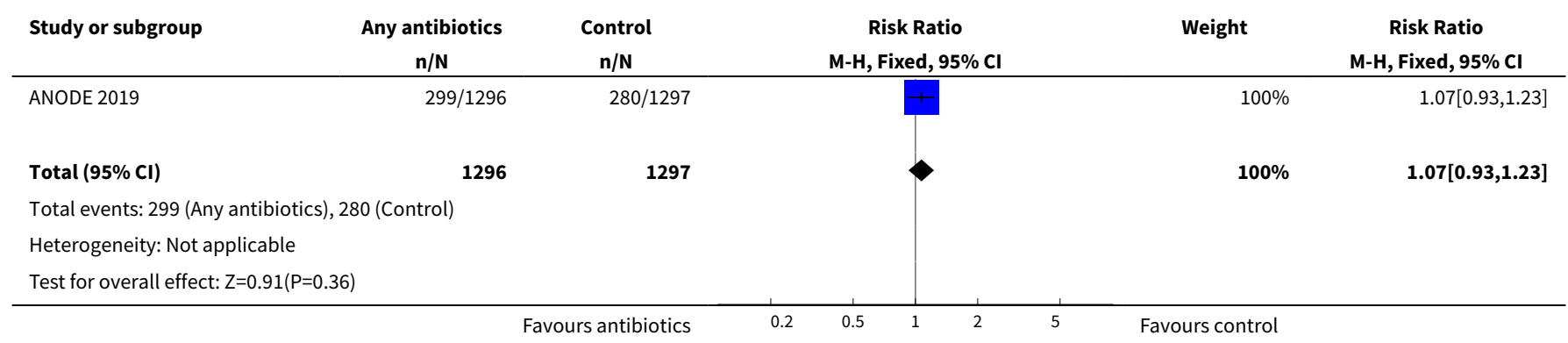

Analysis 1.14. Comparison 1 Any antibiotics versus placebo or no treatment, Outcome 14 Breastfeeding at 6 weeks.

\begin{tabular}{|c|c|c|c|c|c|}
\hline Study or subgroup & $\begin{array}{c}\text { Any antibiotics } \\
\mathrm{n} / \mathrm{N}\end{array}$ & $\begin{array}{c}\text { Control } \\
n / N\end{array}$ & $\begin{array}{c}\text { Risk Ratio } \\
\text { M-H, Fixed, 95\% Cl }\end{array}$ & Weight & $\begin{array}{c}\text { Risk Ratio } \\
\text { M-H, Fixed, } 95 \% \mathrm{Cl}\end{array}$ \\
\hline ANODE 2019 & $662 / 1296$ & $657 / 1297$ & & $100 \%$ & $1.01[0.93,1.09]$ \\
\hline Total $(95 \% \mathrm{Cl})$ & 1296 & 1297 & $\boldsymbol{\gamma}$ & $100 \%$ & $1.01[0.93,1.09]$ \\
\hline \multicolumn{6}{|c|}{ Total events: 662 (Any antibiotics), 657 (Control) } \\
\hline \multicolumn{6}{|c|}{ Heterogeneity: Not applicable } \\
\hline
\end{tabular}

Analysis 1.15. Comparison 1 Any antibiotics versus placebo or no treatment, Outcome 15 Perineum "ever too painful or uncomfortable" to feed baby.

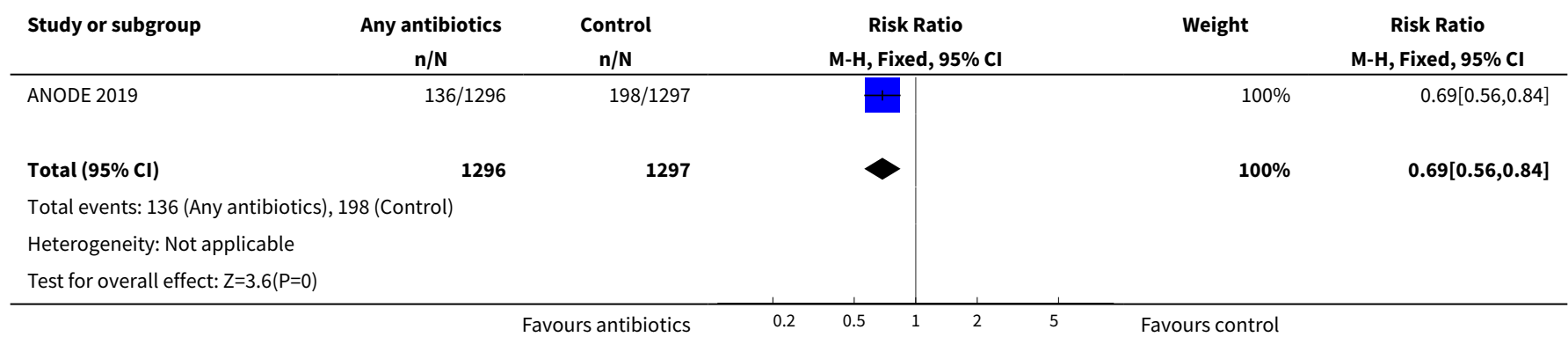

Analysis 1.16. Comparison 1 Any antibiotics versus placebo or no treatment, Outcome 16 Any primary care or home visits in relation to perineum.

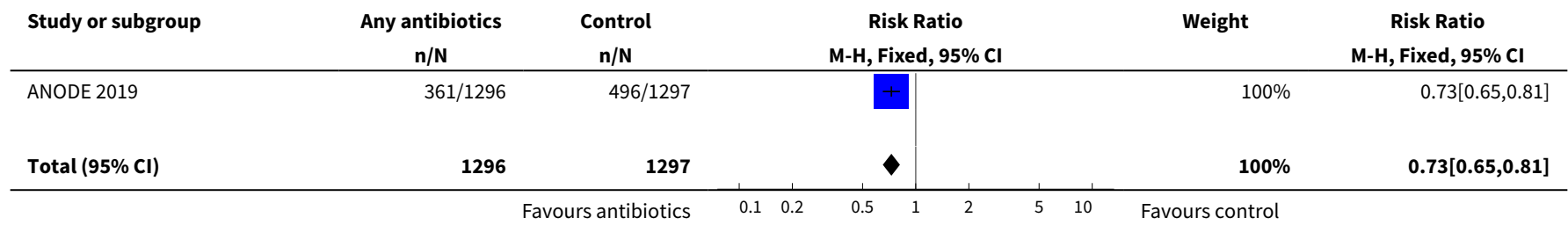




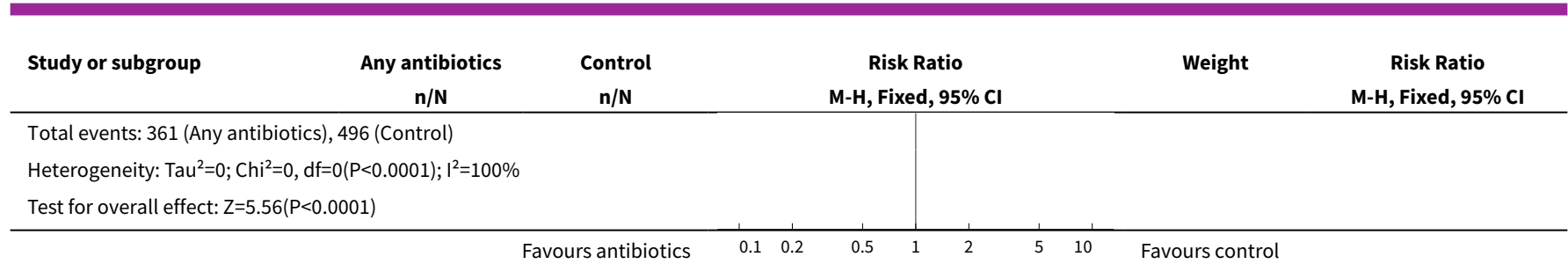

Analysis 1.17. Comparison 1 Any antibiotics versus placebo or no treatment, Outcome 17 Any outpatient visits in relation to perineum.

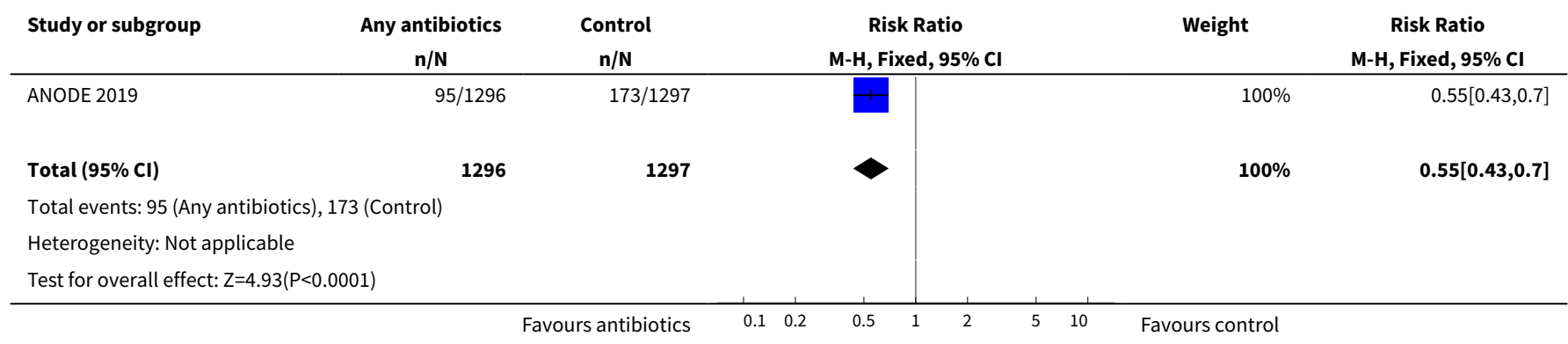

Analysis 1.18. Comparison 1 Any antibiotics versus placebo or no treatment, Outcome 18 Maternal hospital re-admission.

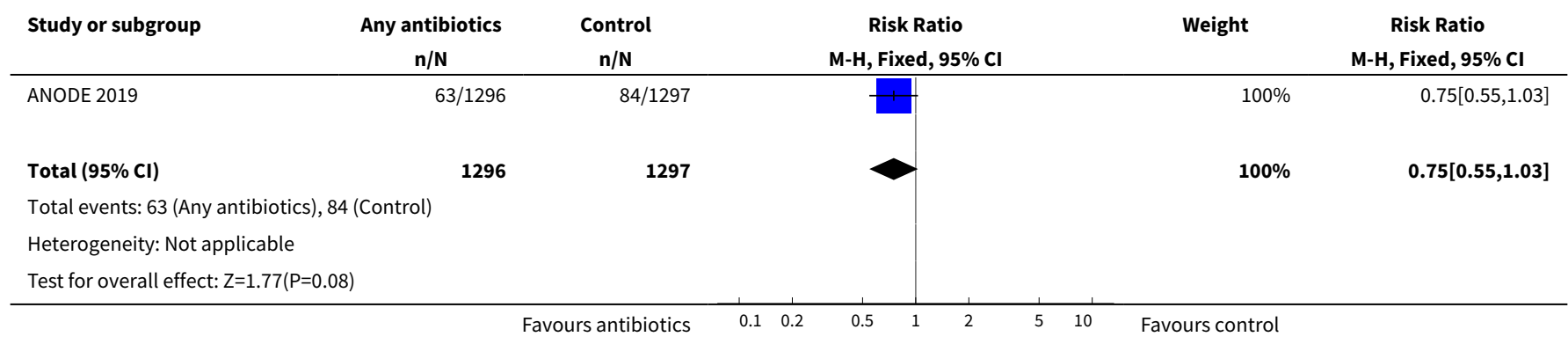

Analysis 1.19. Comparison 1 Any antibiotics versus placebo or no treatment, Outcome 19 Maternal health-related quality of life.

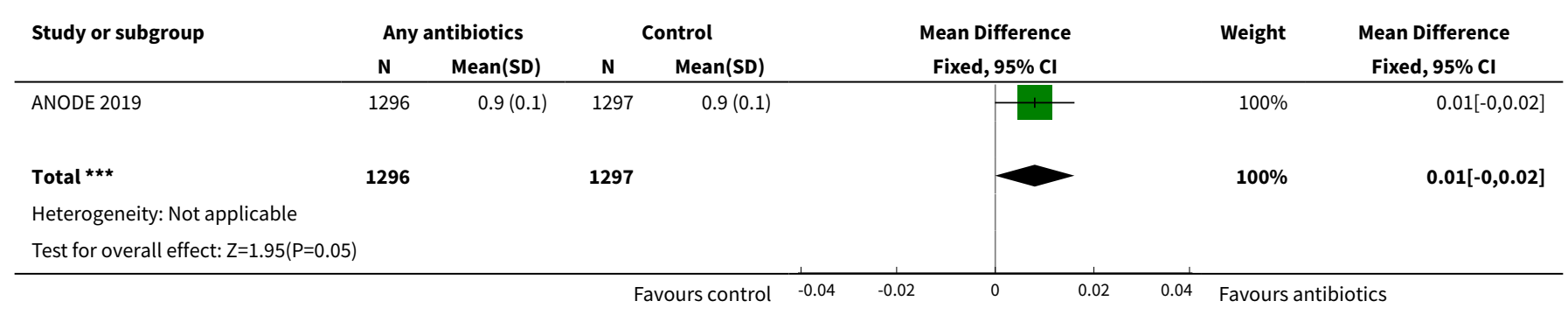


Analysis 1.20. Comparison 1 Any antibiotics versus placebo or no treatment, Outcome 20 Costs ( $£$ ).

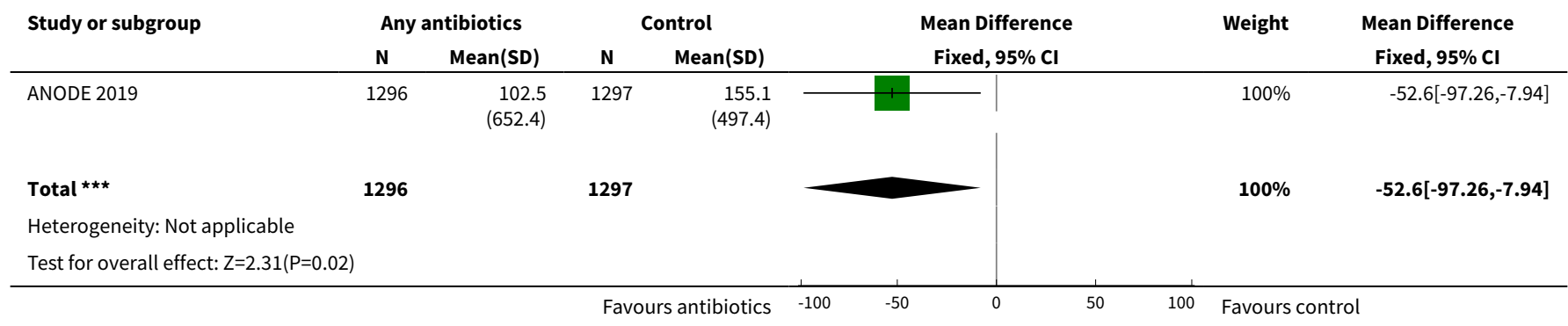

\section{APPENDICES}

\section{Appendix 1. Search terms for ClinicalTrials.gov and ICTRP}

Searched 5 July 2019

\section{ICTRP}

ventouse AND antibiotics

vacuum AND antibiotics

forceps AND antibiotics

operative AND delivery AND antibiotics

\section{ClinicalTrials.gov}

Advanced search

operative delivery | Interventional Studies | antibiotics

forceps | Interventional Studies | antibiotics

ventouse | Interventional Studies | antibiotics

vacuum extraction | Interventional Studies | antibiotics

WHAT'S NEW

\begin{tabular}{lll}
\hline Date & Event & Description \\
\hline 5 July 2019 & $\begin{array}{l}\text { New citation required and conclusions } \\
\text { have changed }\end{array}$ & $\begin{array}{l}\text { Prophylactic intravenous antibiotics are probably effective in re- } \\
\text { ducing infectious puerperal morbidities in women undergoing }\end{array}$ \\
& $\begin{array}{l}\text { operative vaginal deliveries without clinical indications for an- } \\
\text { tibiotic administration after delivery. As the evidence mainly re- }\end{array}$ \\
& sulted from one multi-centre study in a high-income country, \\
& future well-designed randomised trials in other settings are re- \\
& quired to confirm the review findings. \\
\hline
\end{tabular}




\section{H IS T O R Y}

Protocol first published: Issue 4, 2003

Review first published: Issue 3, 2004

\begin{tabular}{|c|c|c|}
\hline Date & Event & Description \\
\hline 12 July 2017 & New search has been performed & $\begin{array}{l}\text { Search updated and one new ongoing study identified (ANODE } \\
\text { 2015a). }\end{array}$ \\
\hline 12 July 2017 & $\begin{array}{l}\text { New citation required but conclusions } \\
\text { have not changed }\end{array}$ & Conclusions remain unchanged. \\
\hline 31 August 2014 & $\begin{array}{l}\text { New citation required but conclusions } \\
\text { have not changed }\end{array}$ & $\begin{array}{l}\text { Review updated. No new trials identified so conclusions remain } \\
\text { unchanged. }\end{array}$ \\
\hline 31 August 2014 & New search has been performed & $\begin{array}{l}\text { Search updated, no further trials identified. Methods updated. } \\
\text { Please note that blinding has now been divided into two assess- } \\
\text { ments: } 1 \text {. Blinding of participants and personnel (performance } \\
\text { bias); and } 2 \text {. Blinding of outcome assessors (detection bias). Ta- } \\
\text { bles have been updated. A 'Summary of findings' table has been } \\
\text { incorporated for this update. }\end{array}$ \\
\hline 12 October 2012 & Amended & The Acknowledgements section has been edited. \\
\hline 18 July 2012 & $\begin{array}{l}\text { New citation required but conclusions } \\
\text { have not changed }\end{array}$ & No new trials identified. \\
\hline 18 July 2012 & New search has been performed & New search for trials conducted and Background updated. \\
\hline 31 August 2008 & New search has been performed & Search updated. No new studies identified. \\
\hline 3 April 2008 & Amended & Converted to new review format. \\
\hline 30 June 2007 & New search has been performed & Search updated. No new trials identified. \\
\hline 31 August 2005 & New search has been performed & Search updated. No new trials identified. \\
\hline 3 April 2004 & Amended & Substantive amendment. \\
\hline
\end{tabular}

\section{CONTRIBUTIONS OF AUTHORS}

Tippawan Liabsuetrakul (TL) gathered background information and wrote the first and final draft of the protocol. TL assessed trial eligibility and methodological quality, extracted data, wrote the first draft of the review and co-ordinated the comments from the other review authors. For the 2008 update, TL reviewed the draft and final version of the updated review. For the 2012, 2014, and 2017 update, TL reviewed and updated the text. For the current 2019 update, TL assessed trial eligibility and methodological quality, extracted data and wrote the draft and final version of the updated review.

Thanapan Choobun (TC) gathered background information and commented on the draft protocol. TC assessed trial eligibility and methodological quality, extracted data and commented on the draft review. For the 2008 update, TC approved the final version of the updated review. For the 2012, 2014, 2017 and the current 2019 update, TC approved the version for publication.

Krantarat Peeyananjarassri (KP) gathered background information and commented on the draft protocol. KP commented on the draft review. For the 2008 update, KP approved the final version of the updated review. For the 2012, 2014, and 2017 update, KP approved the version for publication. For the current 2019 update, KP assessed trial eligibility and methodological quality, extracted data and approved the version for publication. 
Monir Islam (MI) supervised the development of the protocol and review. MI commented on the draft protocol and review. For the 2008 update, MI approved the final version of the updated review. For the 2012, 2014, 2017 and the current 2019 update, MI approved the version for publication.

\section{DECLARATIONS OF INTEREST}

Tippawan Liabsuetrakul: none known.

Thanapan Choobun: none known.

Krantarat Peeyananjarassri: none known.

Q Monir Islam: none known.

\section{SOURCES OF SUPPORT}

\section{Internal sources}

- Faculty of Medicine, Prince of Songkla University, Thailand.

\section{External sources}

- Thailand Research Fund (Distinguished Research Professor Award), Thailand.

- World Health Organization (WHO) and the UNDP-UNFPA-UNICEF-WHO-World Bank Special Programme of Research, Development and Research Training in Human Reproduction (HRP), Switzerland.

This review is supported by funding to Cochrane Pregnancy and Childbirth (University of Liverpool)

\section{DIFFERENCES BETWEEN PROTOCOLANDREVIEW}

Methods updated to current standard PCG methods (2017).

We added in an additional search of ClinicalTrials.gov and the WHO International Clinical Trials Registry Platform (ICTRP).

The primary outcome on infected episiotomy/perineal/vaginal laceration (oedematous, erythematous, wound edge with pain, serosanguineous or frankly purulent material or wound dehiscence) prespecified in the protocol was reported in this updated review as superficial or deep perineal incisional infection, organ or space perineal wound infection and wound breakdown as classified in a study of ANODE 2019.

Confirmed or suspected maternal infection within six weeks of delivery, defined by a new prescription of antibiotics for presumed perineal wound-related infection, endometritis or uterine infection, urinary tract infection with systemic features or infection; confirmed systemic infection on culture; or endometritis (ANODE 2019), non- prespecified in the protocol was added in this update review. Since we assumed by its definition that it included all five prespecified primary outcomes in our protocol (fever, infected episiotomy/perineal/vaginal laceration, endometritis, urinary tract infection, and serious infectious complications), it was added in the primary outcomes, but not the outcomes for GRADE. In addition, the secondary outcomes of this trial (perineal pain, use of pain relief for perineal pain, need for additional perineal care, dyspareunia, breastfeeding at six weeks, perineum "ever too painful or uncomfortable" to feed baby, any primary care or home visits in relation to perineum, any outpatient visit in relation to perineum, maternal hospital re-admission, and maternal health-related quality of life) representing the health consequences of perineal wound infections or pain were also added in the secondary outcomes as nonprespecified in this update review.

The contents in the sections of "Assessment of heterogeneity", "Data synthesis", "Subgroup analysis and investigation of heterogeneity", and "Sensitivity analysis" in this update review were revised from the protocol to make more relevant and valid for the additional included study.

\section{INDEX TERMS}

\section{Medical Subject Headings (MeSH)}

*Antibiotic Prophylaxis; Endometritis [prevention \& control]; Extraction, Obstetrical [ ${ }^{\star}$ adverse effects]; Obstetrical Forceps; Puerperal Infection [ ${ }^{\star}$ prevention \& control]; Randomized Controlled Trials as Topic; Vacuum Extraction, Obstetrical [adverse effects]; Vaginal Diseases [ ${ }^{\star}$ prevention \& control]

\section{MeSH check words}

Female; Humans; Pregnancy 